\title{
Hippocampal Neurons Exhibit Cyclothiazide-sensitive Rapidly Desensitizing Responses to Kainate
}

\author{
Doris K. Patneau, ${ }^{1}$ Ladislav Vyklicky, Jr., ${ }^{2}$ and Mark L. Mayer ${ }^{1}$ \\ 'Laboratory of Cellular and Molecular Neurophysiology, NICHD, NIH, Bethesda, Maryland 20892 and ${ }^{2}$ Institute of \\ Physiology, Academy of Sciences of the Czech Republic, 14220 Prague 4, The Czech Republic
}

In whole-cell recordings from mammalian CNS neurons, AMPA-preferring giutamate receptors exhibit strong desensitization in response to AMPA, glutamate, and quisqualate, but not to kainate or domoate. Such desensitization is reduced by lectins, by the nootropic drug aniracetam, and by diazoxide. None of these compounds strongly modulate responses to kainate and domoate, consistent with the apparent lack of desensitization to these agonists. We now report experiments on hippocampal neurons in which responses to kainate were strongly potentiated by cyclothiazide, a benzothiadiazine diuretic and antihypertensive drug structurally related to diazoxide. Cyclothiazide increased the maximum response to a saturating concentration of kainate by approximately $300 \%$ and produced a shift to the left in the kainate dose-response curve. Because cyclothiazide was considerably more effective than aniracetam in reducing desensitization evoked by glutamate, we tested the possibility that potentiation of responses to kainate was due to block of a previously undetected component of desensitization in the response to kainate itself. In outside-out patches responses to rapid perfusion of $3 \mathrm{~mm}$ kainate showed $34 \%$ desensitization, the onset of which developed with a time constant of $\mathbf{2 . 2}$ msec. Desensitization of responses to kainate was abolished by $100 \mu \mathrm{M}$ cyclothiazide, as was the much stronger desensitization evoked by glutamate and AMPA. Cyclothiazide also slowed the rate of deactivation of responses to kainate recorded after return to agonist-free solution. Current-voltage plots for control responses to kainate exhibited outward rectification that was associated with a reduction in the amount of desensitization on depolarization. Both effects were absent in the presence of cyclothiazide, suggesting that rectification of responses to kainate was due to the voltage dependence of desensitization. The complete block of desensitization produced by cyclothiazide provides a powerful new tool for analysis of allosteric regulatory mechanisms at AMPA-preferring glutamate receptors.

[Keywords: kainate, AMPA, desensitization, hippocampus, excitatory amino acids, cyclothiazide, glutamate receptor, allosteric regulation, concentration jumpJ

Received Nov. 25, 1992; revised Feb. 3, 1993; accepted Feb. 24, 1993.

We thank Christine Winters for preparation of cell cultures, Drs. C. E. Jahr and G. L. Westbrook for advice on constructing the piezoelectric element perfusion system, Dr. M. J. Benveniste for reading the manuscript, and Drs. K. Yamada and $S$. Rothman for sharing results prior to publication.

Correspondence should be addressed to Dr. M. L. Mayer, Building 49, Room 5A78, National Institutes of Health, Bethesda, MD 20892.

Copyright $(1993$ Society for Neuroscience $0270-6474 / 93 / 133496-14 \$ 05.00 / 0$
Glutamate receptors in the rat CNS are known to be formed from several gene families (Sommer and Seeburg, 1992). Experiments on receptors generated using in vitro expression systems provide evidence for AMPA-preferring subtypes assembled from combinations of glutamate receptor subunits GluR1GluR4 (Boulter et al., 1990), also referred to as GluR-A through GluR-D (Keinänen et al., 1990), and kainate-preferring subtypes assembled from GluR5-GluR7 (Bettler et al., 1990, 1992; Egebjerg et al., 1991) most likely in combination with KA1 and KA2 (Werner et al., 1991; Herb et al., 1992). At AMPA-preferring glutamate receptors, kainate acts with low potency and produces nondesensitizing responses while AMPA and glutamate produce rapidly and strongly desensitizing responses (Sommer et al., 1990). In contrast, kainate is a potent agonist at kainate-preferring glutamate receptors and produces strongly desensitizing responses while AMPA is inactive or of very low potency (Egebjerg et al., 1991; Herb et al., 1992). Numerous studies have reported nondesensitizing responses to kainate and domoate and rapidly desensitizing responses to AMPA, glutamate, and quisqualate in hippocampal neurons, consistent with the expression of AMPA-preferring glutamate receptors (e.g. Kiskin et al., 1986; Trussell et al., 1988; Mayer and Vyklicky, 1989; Patneau and Mayer, 1990, 1991; Jonas and Sakmann, 1992). Compared to their action on hippocampal neurons, kainate and domoate are more potent agonists at dorsal root ganglion (DRG) neurons and produce strongly desensitizing responses, consistent with the expression of kainate-preferring receptors in sensory neurons (Huettner, 1990; Wong et al., 1992).

The different functional response of hippocampal neurons to AMPA and kainate raises the question as to why some agonists produce desensitization at AMPA-preferring receptors while others apparently do not. Previously we characterized the actions of a series of willardiines on hippocampal neurons and proposed that agonist-dependent differences in relative affinity for the active and desensitized states of AMPA-preferring glutamate receptors could account for variation in the degree of desensitization evoked by different agonists (Patneau et al., 1992a). According to this hypothesis, kainate binds to the desensitized state(s) of AMPA-preferring glutamate receptors with much lower attinity than does AMPA, glutamate, or quisqualate (Patneau and Mayer, 1991; Mayer et al., 1992). Our hypothesis raised two issues. First, kainate might indeed produce desensitization at AMPA-preferring glutamate receptors, but less profound than occurs with AMPA or glutamate, and too rapid to measure with whole-cell recording. Second, substances that reduce desensitization at AMPA receptors should potentiate responses to kainate. The lectins and drugs that have been tested previously for activity at AMPA-preferring glutamate receptors 
have relatively weak effects on desensitization. Although aniracetam $(5 \mathrm{~mm})$ produces nearly 10 -fold potentiation of equilibrium responses to glutamate, substantial (84\%) desensitization still occurs in the presence of $5 \mathrm{~mm}$ aniracetam (Vyklicky et al., 1991). The relief of desensitization at AMPA-preferring glutamate receptors by the lectins concanavalin A and WGA is even less than produced by aniracetam (Mayer and Vyklicky, 1989; Vyklicky et al., 1991), and suggests that these substances fail to affect responses to kainate because their effect on desensitization is weak.

The recent discovery that diazoxide and some structurally related derivatives are considerably more efficacious than aniracetam in reducing desensitization at AMPA-preferring glutamate receptors (Yamada and Rothman, 1991, 1992; Yamada, 1992) offered the possibility to reexamine whether desensitization is evoked by kainate. We report here experiments that show that kainate produces substantial, but very rapid, desensitization at AMPA-preferring glutamate receptors in hippocampal neurons, and that such desensitization is completely blocked by cyclothiazide, a benzothiadiazine related in structure to diazoxide (Yamada, 1992).

\section{Materials and Methods}

Cell culture and recording techniques. Newborn Sprague-Dawley rats were killed by decapitation, and the hippocampi dissected. Neurons were plated on a confluent glial cell feeder layer as previously described (Mayer et al., 1989). Experiments were performed at room temperature $\left(24-27^{\circ} \mathrm{C}\right) 3-14 \mathrm{~d}$ after neurons were plated. Whole-cell recording at a holding potential of $-60 \mathrm{mV}$ was performed with an Axoclamp 2 amplifier (Axon Instruments) in conjunction with a stepper motor-based perfusion system capable of switching solutions with an exchange time constant of $\leq 10 \mathrm{msec}$ (Vyklicky et al., 1990). Outside-out patches were voltage-clamped at $-60 \mathrm{mV}$ using a List EPC-7 amplifier; the majority of experiments used standard outside-out patches, but two other configurations were also used. The action of kainate and cyclothiazide was similar in all patch configurations. Nucleated patches were formed as described by Sather et al. (1992). In experiments with nystatin-perforated vesicles (Levitan and Kramer, 1990), pipettes were backfilled with intracellular solution containing $100 \mu \mathrm{g} / \mathrm{ml}$ nystatin after first loading the tip with nystatin-free solution (Horn and Marty, 1988). Vesicles were formed by slowly withdrawing the pipette after first forming a gigaseal. Solutions were applied to patches using four-barreled glass tubing (Vitro Dynamics) pulled to a width of approximatcly $250 \mu \mathrm{m}$ and held by a piezo translator driven by a high-voltage power supply (Physik Instrumente P-245-30 and P-272). Upon charging and discharging of the piezo element, the interface of a pair of solutions was rapidly moved across the patch; the $10-90 \%$ rise time for open tip junction potentials recorded on switching between solutions of different ionic composition was typically $<200 \mu \mathrm{sec}$. Data were filtered at $1-3$ $\mathrm{kHz}$ and sampled on line at $2-20 \mathrm{kHz}$ using pcLAMP software (Axon Instruments).

Solutions. Extracellular solution contained (in $\mathrm{mm}$ ) $160 \mathrm{NaCl}, 2.5$ $\mathrm{KCl}, 2 \mathrm{CaCl}_{2}, 1 \mathrm{MgCl}_{2}, 10 \mathrm{HEPES}, 10$ glucose, and $0.01 \mathrm{mg} / \mathrm{ml}$ phenol red. The pH was titrated to 7.3 with $\mathrm{NaOH}$, and osmolarity was adjusted to $325 \mathrm{mOsm}$ with sucrose if necessary. In some whole-cell experiments $60-110 \mathrm{mM} \mathrm{NaCl}$ was replaced by sucrose to reduce the driving force for agonist-evoked currents that were often too large to voltagc-clamp in the presence of cyclothiazide; $400 \mathrm{nM}$ tetrodotoxin and $5 \mu \mathrm{M}$ bicuculline methochloride were added to block sodium currents and inhibitory postsynaptic currents, respectively. In experiments with L-glutamate, $500 \mathrm{nM}$ MK-801 or $10 \mu \mathrm{M}$ D-aminophosphonovaleric acid was added to eliminate any residual activation of NMDA receptors (the extracellular solution contained $1 \mathrm{~mm} \mathrm{Mg}$ and no added glycine). Borosilicate glass electrodes for whole-cell recording contained (in mM) 125 CsMeSO $3,15 \mathrm{CsCl}, 10 \mathrm{HEPES}, 5 \mathrm{BAPTA}$ or EGTA, $0.5 \mathrm{CaCl}_{2}, 3 \mathrm{MgCl}_{2}$, and $2 \mathrm{Na}_{2} \mathrm{ATP}$; $\mathbf{p H}$ was adjusted to 7.2 with $\mathrm{CsOH}$ and osmolarity to 305 mOsm with sucrose; $10 \mathrm{~mm} \mathrm{CsMeSO}_{3}$ was replaced by $10 \mathrm{~mm} \mathrm{CsF}$ in some outside-out patch recordings.

Cyclothiazide was a gift from Lilly Research Laboratories (Indianapolis, IN); MK-801, from Merck, Sharp and Dohme (Rahway, NJ); and aniracetam, from Hoffman-La Roche (Nutley, NJ). Cyclothiazide and aniracetam were dissolved in dimethyl sulfoxide (DMSO) at 20 and 500 $\mathrm{mM}$, respectively, before dilution with extracellular solution. In several experiments the control solution also contained $0.5 \%$ DMSO (the concentration present in extracellular recording solution containing $100 \mu \mathrm{M}$ cyclothiazide). Salts, biochemicals, and excitatory amino acids were purchased from Aldrich, Diagnostic Chemicals, Molecular Probes, Sigma, and Tocris Neuramin.

Analysis. In many cases agonist-evoked currents exhibited significant rundown, particularly in outside-out patches; this was time dependent rather than activity dependent, and apparently unaffected by cyclothiazide, suggesting that rundown is not due to a cyclothiazide-sensitive, absorbing desensitized state. The rundown was much slower in wholecell recording, in nucleated macropatches, and in nystatin vesicles. Whenever possible control responses recorded before and after an experimental manipulation were used to correct for rundown. In comparisons between agonists (e.g., kainate and glutamate) applications were alternated and several sequential responses averaged. Because the washout of cyclothiazide was so slow, analysis of the degree of potentiation by cyclothiazide was performed by comparing control responses immediately preceding the application of cyclothiazide with the first few potentiated responses. Decay time constants and rates of onset of desensitization were fit with one or the sum of two exponentials using pCLAMP (Axon Instruments). Dose-response curves were fit to the equation

$$
I=I_{\max } \times\left(1 /\left(1+\left(\mathrm{EC}_{50} /[\text { ligand }]\right)^{n}\right)\right)
$$

where $I_{\max }$ is the response at a saturating concentration of ligand; $\mathrm{EC}_{50}$, the concentration of ligand producing a half-maximal response; [ligand], the concentration of ligand; and $n$, the Hill coefficient. Data are given as mean \pm standard error of the mean (SEM) unless noted otherwise.

\section{Results}

\section{Potentiation of responses to kainate by cyclothiazide}

Several recent reports have shown modulation of desensitization at AMPA-preferring glutamate receptors by the drugs aniracetam (Ito et al., 1990; Isaacson and Nicoll, 1991; Tang et al., 1991; Vyklicky et al., 1991) and diazoxide (Yamada and Rothman, 1991; Yamada and Rothman, 1992). Both of these drugs were reported to potentiate selectively responses evoked by AMPA, glutamate, and quisqualate but not NMDA or kainate (Ito et al., 1990; Isaacson and Nicoll, 1991; Yamada and Rothman, 1992). In contrast to these previous negative reports, we found that $5 \mathrm{~mm}$ aniracetam, the highest concentration we could achieve in physiological solutions, produced weak potentiation of responses to a saturating $(6 \mathrm{~mm})$ concentration of kainate (Fig. $2 A$ ); on average, responses were $1.08 \pm 0.02$ times larger than control (four cells). Cyclothiazide, a benzothiadiazine that is structurally related to diazoxide (Fig. 1), but more potent in reducing desensitization at AMPA-preferring glutamate receptors (Patneau et al., 1992b; Yamada, 1992), produced marked potentiation of responses to kainate (Fig. $2 B$ ). With 30 $\mu \mathrm{M}$ cyclothiazide, responses to $6 \mathrm{mM}$ kainate were $3.3 \pm 0.18$ times larger than control (four cells). The effects of both aniracetam and cyclothiazide were readily reversible (Fig. 2), although more than $3 \mathrm{~min}$ was required for complete recovery from potentiation evoked by cyclothiazide (see below).

\section{Dose-response analysis}

Preliminary experiments revealed much greater potentiation of responses to kainate by cyclothiazide at low compared to high doses of agonist. For the records illustrated in Figure $3 A$, the response to $20 \mu \mathrm{M}$ kainate showed 29.5 -fold potentiation by 100 $\mu \mathrm{M}$ cyclothiazide, while for $1 \mathrm{~mm}$ kainate there was only 3.2fold potentiation. This suggested that cyclothiazide produces a leftward shift in the dose-response curve for kainate and appropriate analysis revealed a decrease in the $\mathrm{EC}_{50}$ for kainate, 
<smiles>COc1ccc(C(=O)N2CCCC2=O)cc1</smiles>

\section{Diazoxide}<smiles>CC1=Nc2ccc(Cl)cc2S(=O)(=O)N1</smiles>

\section{Cyclothiazide}<smiles>O=S1(=O)NC(C2CC3C=CC2C3)Nc2cc(Cl)c(S(=O)(=O)O)cc2O1</smiles>

Figure 1. Three drugs that modulate desensitization at AMPA-preferring glutamate receptors. Aniracetam is a nootropic drug of unknown mechanism of action that potentiates agonist responses and slows the rate of onset of desensitization at AMPA-preferring glutamate receptors (Isaacson and Nicoll, 1991; Tang et al., 1991; Vyklicky et al., 1991). Diazoxide and cyclothiazide are structurally related benzothiadiazines that potentiate responses at AMPA-preferring glutamate receptors by a mechanism distinct from their cardiovascular and renal actions (Yamada, 1992; Yamada and Rothman, 1992).

from a control value of $142 \pm 11.7 \mu \mathrm{M}$ (six cells) to $48 \pm 2.7$ $\mu \mathrm{M}$ (seven cells) in the presence of $30 \mu \mathrm{M}$ cyclothiazide (Fig. $3 B$ ), with little change in apparent Hill coefficient (control, $1.25 \pm$ 0.05 ; cyclothiazide, $1.30 \pm 0.06$ ) but a 3.7 -fold increase in amplitude of the response to a maximally effective concentration of kainate.

The $\mathrm{EC}_{50}$ for kainate was similar to that determined previously in cultured mouse hippocampal neurons $(143 \mu \mathrm{M}$; Patneau and Mayer, 1990), but substantially different from values determined using patches obtained from pyramidal neurons in areas CA1 $(474 \mu \mathrm{M})$ and CA3 $(344 \mu \mathrm{M})$ of rat hippocampal slices (Jonas and Sakmann, 1992). These differences in apparent affinity could reflect changes in receptor properties in adult versus embryonic neurons or the use of whole-cell versus outside-out patch-clamp recording techniques. To examine the latter possibility, we measured the dose-response relationship for kainate in outside-out patches. The $\mathrm{EC}_{50}(264 \pm 12 \mu \mathrm{M}, n=5)$ was larger than obtained with whole-cell recording, but still smaller than the values obtained by Jonas and Sakmann (1992). However, in the presence of cyclothiazide the $\mathrm{EC}_{50}$ for kainate in outside-out patches $(53 \pm 6.1 \mu \mathrm{M}, n=7)$ was similar to the value obtained using whole-cell recording.
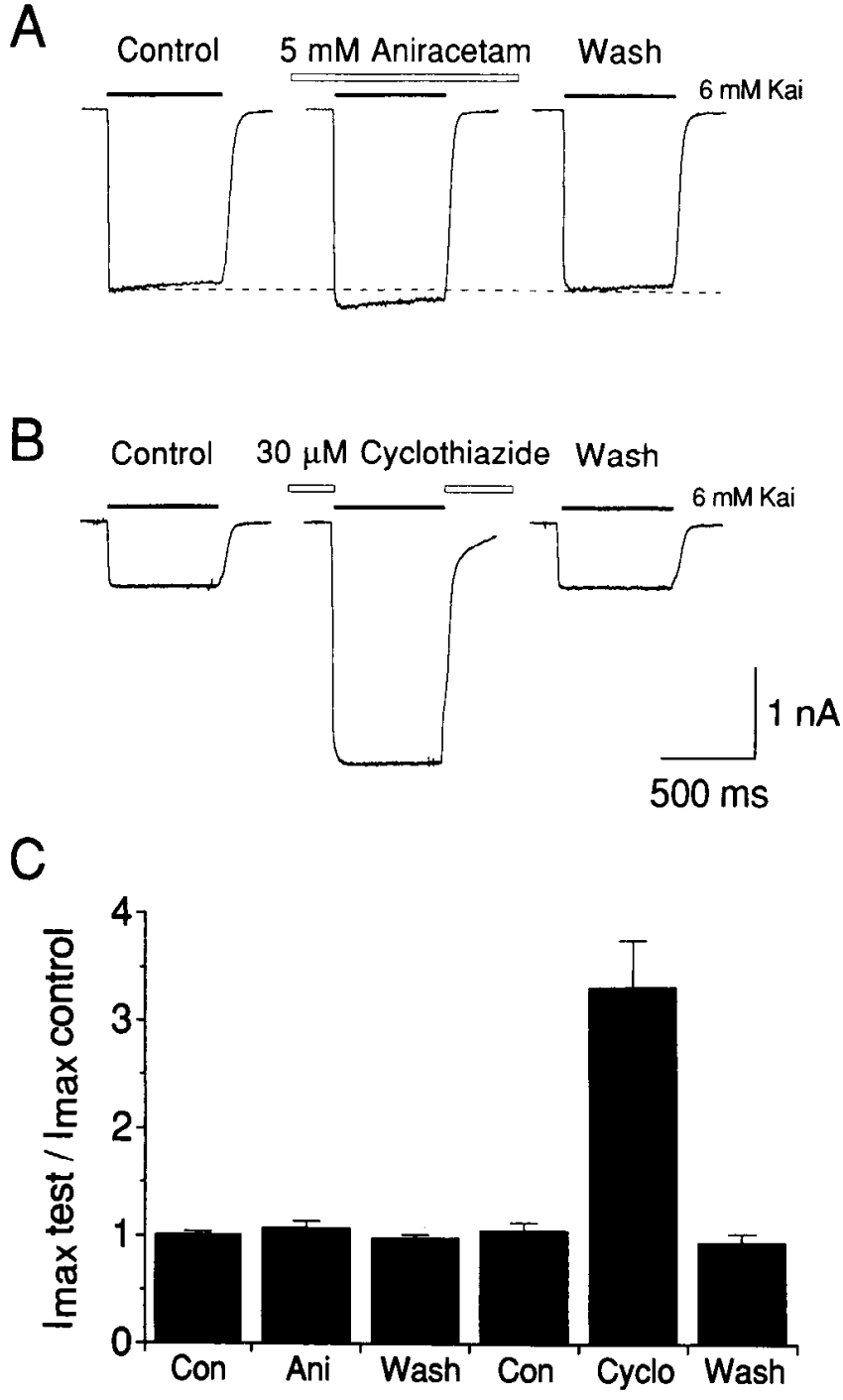

Figure 2. Cyclothiazide but not aniracetam produces strong potentiation of responses to kainate. $A$ and $B$ show whole-cell responses to 6 mM kainate applied for $600 \mathrm{msec}$ (solid bars) before, during, and after application of $5 \mathrm{~mm}$ aniracetam or $30 \mu \mathrm{M}$ cyclothiazide. Responses in $A$ and $B$ are from two neurons in which the maximum response to kainate was of different amplitude. In $A$, aniracetam was applied at the limit of solubility in physiological saline. In $B$, cyclothiazide was applied at a dose close to maximal effectiveness for potentiation of responses to kainate; cyclothiazide was not present during the application of kainate in order to allow measurement of potentiation independent of depression (e.g., Fig. 8). $C$ summarizes results from experiments on eight neurons tested with aniracetam or cyclothiazide; data points show mean \pm SD of six or seven observations per drug.

Previous analysis of the effects of aniracetam on desensitization evoked by glutamate (Vyklicky et al., 1991) suggested that stronger potentiation of responses to kainate would be obtained if the effect of aniracetam at concentrations greater than $5 \mathrm{~mm}$ was examined; due to the limited solubility of aniracetam in physiological saline this was not possible. Of several benzothiadiazine derivatives that modulate responses at AMPApreferring glutamate receptors (Yamada, 1992) we found that only cyclothiazide was soluble over a sufficient concentration range to allow construction of a complete dose-response curve for modulation of responses to kainate (Fig. 4). The $\mathrm{EC}_{50}$ for potentiation of responses to $1 \mathrm{~mm}$ kainate by cyclothiazide was 

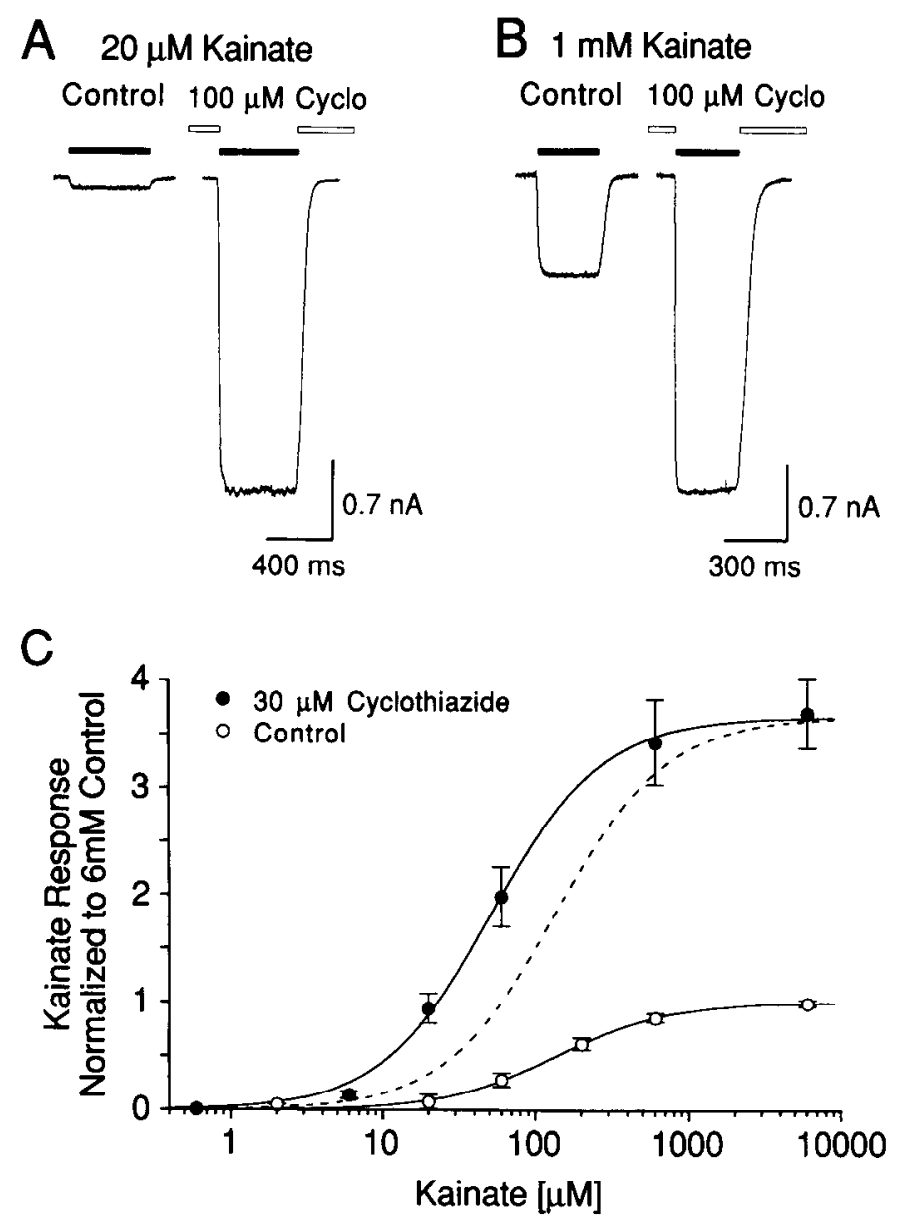

Figure 3. Potentiation by cyclothiazide reflects increases in both maximum response and agonist potency. $A$ and $B$ compare potentiation by $100 \mu \mathrm{M}$ cyclothiazide of responses to $20 \mu \mathrm{M}(A)$ and $1 \mathrm{mM}(B)$ kainate. Responses in $A$ and $B$ are from different neurons, but similar results were obtained in cells tested with several doses of kainate: potentiation by cyclothiazide decreased with increase in dose of kainate. Cyclothiazide potentiated the response to $20 \mu \mathrm{M}$ kainate 29.5 -fold $(A)$, but potentiation was only 3.2 -fold for $1 \mathrm{~mm}$ kainate $(B)$. Dose-response analysis for kainate $(C)$ revealed an increase in agonist potency in the presence of cyclothiazide. Data points show mean $\pm \mathrm{SD}$ of responses normalized to those evoked by $6 \mathrm{~mm}$ kainate in the absence of cyclothiazide, and are fit with Equation 1: control (six cells), $\mathrm{EC}_{50}=135 \mu \mathrm{M}, n=1.2 ; 30$ $\mu \mathrm{M}$ cyclothiazide (seven cells), $\mathrm{EC}_{50}=52 \mu \mathrm{M}, n=1.2$. In the presence of cyclothiazide there was a 3.6 -fold increase in $I_{\max }$. The dashed line illustrates the dose-response curve for kainate predicted if cyclothiazide produced no change in $\mathrm{EC}_{50}$ with the same change in $I_{\max }$ as observed in the presence of cyclothiazide. Perfusion with cyclothiazide was discontinued when kainate was applied to avoid distortion of the doseresponse curve for kainate due to cyclothiazide-evoked depression (e.g., Fig. 8).

$8.6 \pm 0.5 \mu \mathrm{M}$ (four cells), with an apparent Hill coefficient of $1.20 \pm 0.03$. With $100 \mu \mathrm{M}$ cyclothiazide, the amplitude of responses to $1 \mathrm{~mm}$ kainate was $4.15 \pm 0.38$ times larger than control. The maximum possible degree of potentiation calculated from the equation used to fit dose-response curves, assuming a saturating dose of cyclothiazide, was 4.32-fold; thus, at $100 \mu \mathrm{M}$ cyclothiazide produces $96 \%$ of its maximal effect, and this concentration was used in the majority of subsequent experiments.

Together, these results indicate that at high concentrations of kainate potentiation by cyclothiazide results almost completely from an increase in amplitude of the maximum response and
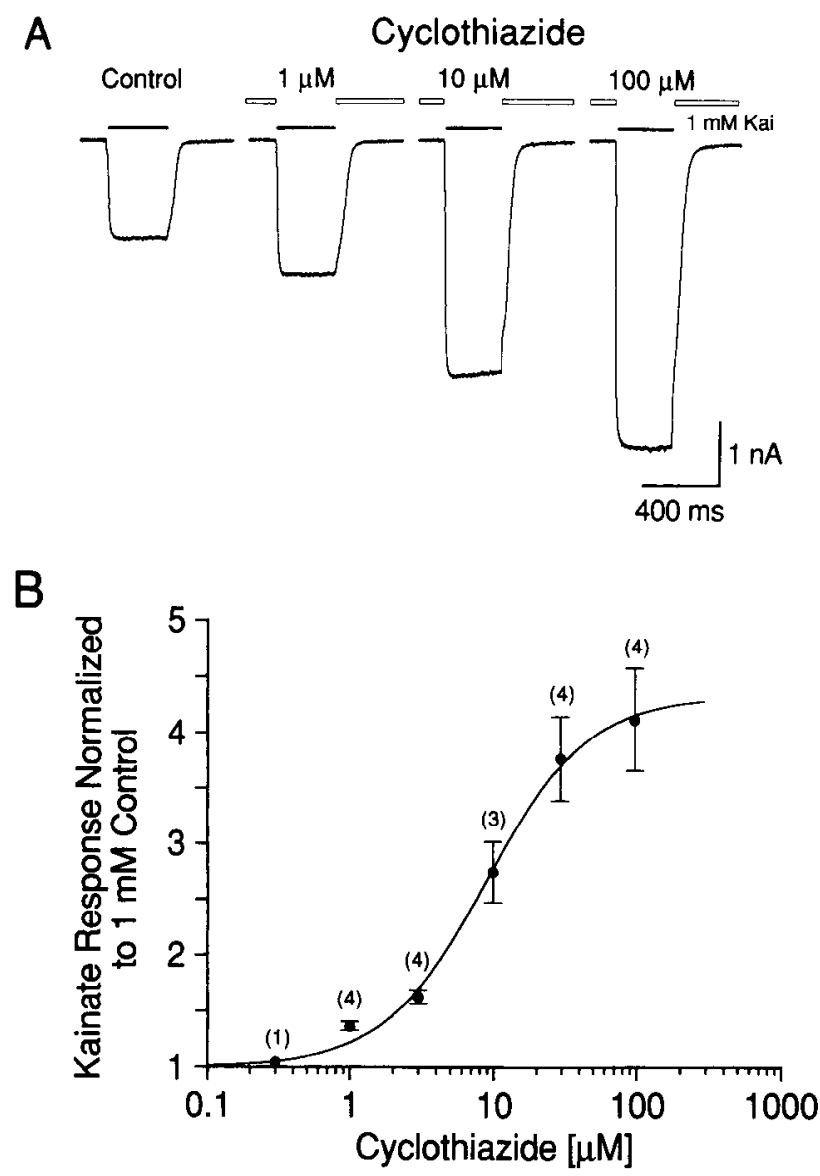

Figure 4. Cyclothiazide is a potent modulator of responses to kainate. $A$ shows potentiation of whole-cell responses to $1 \mathrm{~mm}$ kainate applied for $300 \mathrm{msec}$ by 1,10 , and $100 \mu \mathrm{M}$ cyclothiazide; application of cyclothiazide was discontinued during the application of kainate to allow measurement of potentiation independent of depression (e.g., Fig. 8). The dose-response curve in $B$ summarizes pooled results. Responses in the presence of cyclothiazide were normalized with respect to the response to $1 \mathrm{~mm}$ kainate recorded in the absence of cyclothiazide (values in parentheses indicate the number of cells tested at each dose); data points show mean $\pm S E M$, and were fit to Equation 1 with parameters of $E_{50}$ $=9.0 \mu \mathrm{M}, n=1.2$, and $I_{\max }-4.3$ times larger than control.

suggest that kainate normally acts as a partial agonist. Several possible mechanisms can produce partial agonist action at ligand-gated ion channels, including a low probability for ion channel opening, ion channel block by agonist, and desensitization (c.g., Colquhoun and Ogden, 1988). Although desensitization of responses to kainate at AMPA-preferring glutamate receptors in the mammalian CNS has not been reported previously, a recent study of glutamate receptors in the chick cochlear nucleus described weakly, but rapidly desensitizing responses to high concentrations of kainate (Raman and Trussell, 1992). If kainate produces desensitization at AMPA-preferring glutamate receptors in rat hippocampal neurons, block of desensitization by cyclothiazide could underlie the potentiation of responses to kainate.

\section{Rapidly desensitizing responses to kainate in outside-out patches}

The limited rate of solution exchange that can be achieved during whole-cell recording from hippocampal neurons would be expected to mask the occurrence of desensitization developing 
A

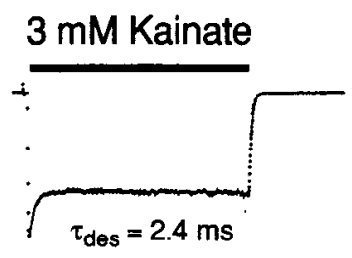

\section{$1 \mathrm{mM}$ Glutamate}

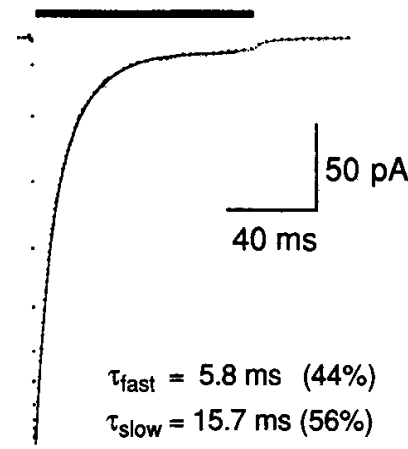

B
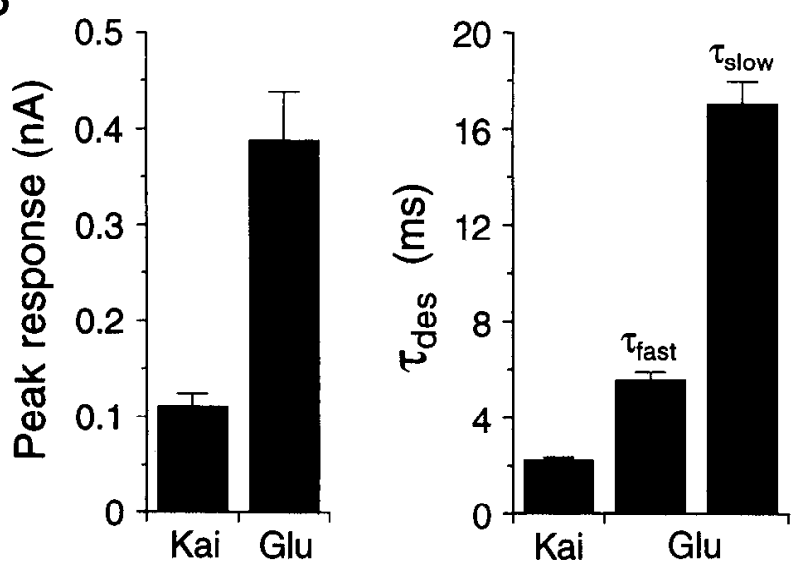

Figure 5. Rapidly desensitizing responses to kainate in outside-out patches from hippocampal neurons. $A$ shows responses of the same patch (nystatin vesicle configuration) to $3 \mathrm{~mm}$ kainate and $1 \mathrm{~mm} S$-glutamate. In this patch, both agonists produced desensitizing responses, but the peak amplitude of the response to kainate was only 0.36 of that to glutamate; desensitization evoked by kainate $(31 \%)$ was also less than for glutamate $(97 \%)$. The onset of desensitization of the response to kainate was well fit by a single exponential function $\left(\tau_{\text {des }}, 2.4 \mathrm{msec}\right)$; desensitization of the response to glutamate developed less rapidly and was best fit by the sum of two exponentials $\left(\tau_{\text {fast }}, 5.8 \mathrm{msec} ; \tau_{\text {slow }}, 15.7\right.$ msec). $B$ summarizes results obtained from 16 patches (mean \pm SEM). In every patch the amplitude of peak responses to kainate was smaller than that to glutamate and exhibited less desensitization, although desensitization developed much faster for kainate than glutamate.

with very rapid kinetics. Whole-cell responses to kainate do occasionally cxhibit a small degrec of fast descnsitization, similar to that evoked by AMPA, but such responses are recorded too infrequently for systematic analysis (D. K. Patneau and M. L. Mayer, unpublished observations). In each of 37 outside-out patches included in this study [33 conventional outside-out patches (Hamill et al., 1991), 2 nucleated patches (Sather et al., 1992), and 2 nystatin-perforated vesicles (Levitan and Kramer, 1990)], responses to $3 \mathrm{~mm}$ kainate exhibited substantial (34 \pm $11.8 \%$, mean $\pm \mathrm{SD}$ ) and rapid (single exponential time constant, $2.2 \pm 0.5 \mathrm{msec}$ ) desensitization (Fig. 5). The onset of desensitization in response to kainate was much faster than previously reported for responses to AMPA and glutamate at AMPA-preferring glutamate receptors on hippocampal neurons for which single exponential fits typically give time constants around 10
A
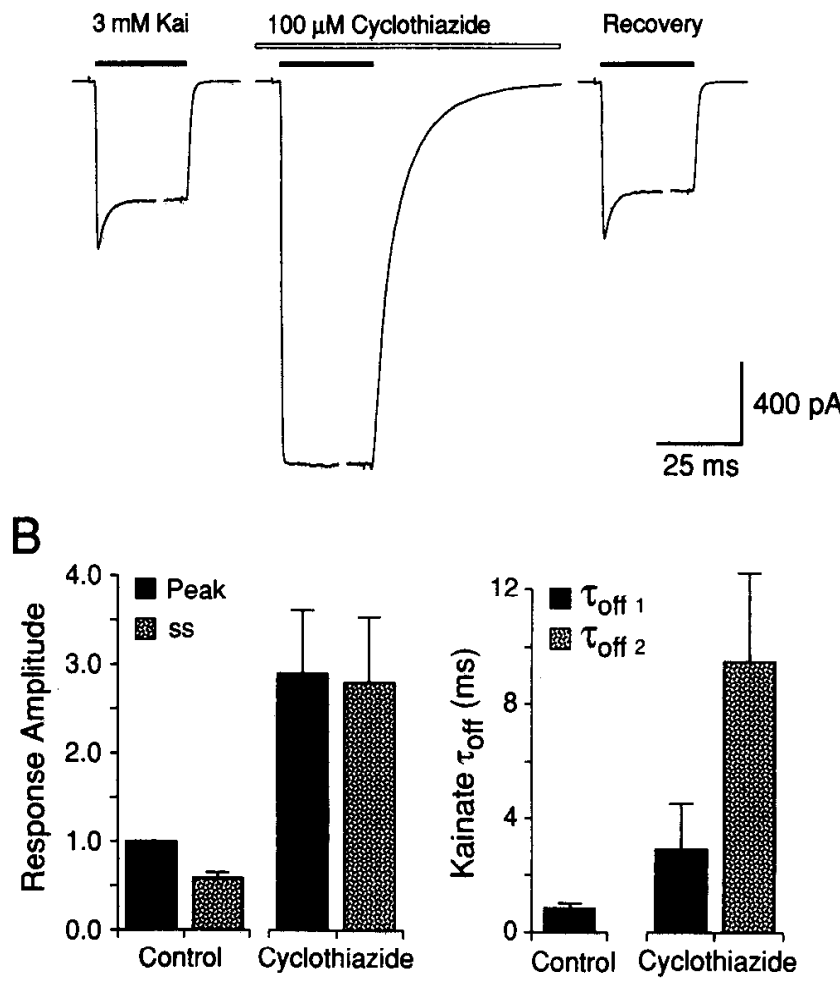

Figure 6. Cyclothiazide blocks desensitization produced by kainate. $A$ shows responses of a nucleated patch to rapid application of $3 \mathrm{~mm}$ kainate before, during, and $240 \mathrm{sec}$ after application of $100 \mu \mathrm{M}$ cyclothiazide (each trace is the average of three responses evoked at 4 sec intervals). Kainate was applied for $100 \mathrm{msec}$, but only the start and end of the agonist responses are illustrated; note that in addition to blocking desensitization, cyclothiazide produced a $200 \%$ increase in amplitude of the peak response to kainate, and a dramatic slowing of the rate of decay of the kainate-activated current recorded following return to agonist-free solution. $B$ summarizes results from 14 patches (mean \pm SD). Amplitude measurements are normalized with respect to the peak of the control response to kainate. The small difference in mean amplitude of peak and steady-state ( $s s$ ) responses in the presence of cyclothiazide most likely reflects the averaging of only three to five points per trace for the peak but 200 points for the steady-state response to kainate. The kinetics of decay of responses to kainate following a switch to agonistfree solution $\left(\tau_{\text {off }}\right)$ were fit with one (control) or the sum of two exponentials (cyclothiazide).

msec (e.g., Mayer and Vyklicky, 1989; Patneau and Mayer, 1991; Tang et al., 1991; Jonas and Sakmann, 1992).

We therefore made a direct comparison between kainate and glutamate, using 15 conventional outside-out-patches and 1 nystatin-perforated vesicle to which both agonists were applied (Fig. 5). Although responses to $50 \mathrm{msec}$ applications of $3 \mathrm{~mm}$ kainate desensitized by only $29.2 \pm 3.3 \%$ while responses to $1 \mathrm{~mm}$ glutamate desensitized by $97.4+0.3 \%$, the onset of desensitization evoked by kainate occurred much faster than for responses evoked by glutamate (Fig. 5). The onset of desensitization produced by kainate was well fit by a single exponential function of time constant $2.2 \pm 0.11 \mathrm{msec}$, while for glutamate desensitization was best fit by the sum of two exponentials, of time constants $\tau_{\text {fast }}=5.6 \pm 0.32 \mathrm{msec}$ and $\tau_{\text {slow }}=17.0 \pm 0.94$ msec, with a relative amplitude of the fast component of $62 \pm$ $4 \%$. To permit a more direct comparison between the rate of desensitization for these agonists, the onset of desensitization for glutamate was also fit with a single exponential; the time constant, $8.8 \pm 0.73 \mathrm{msec}$, was fourfold slower than for kainate, 
A

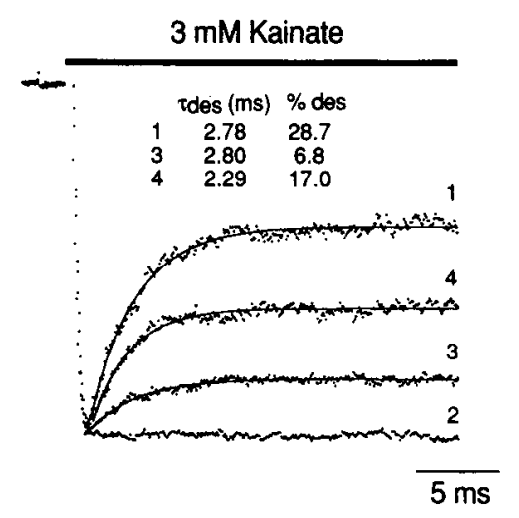

B

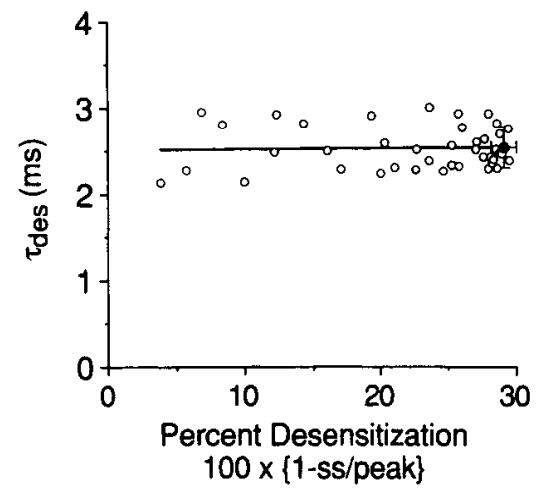

C

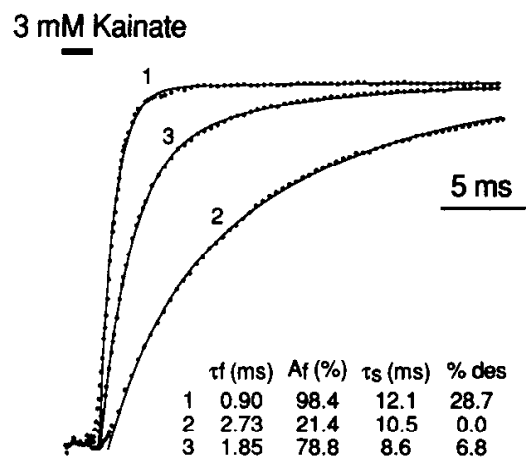

D

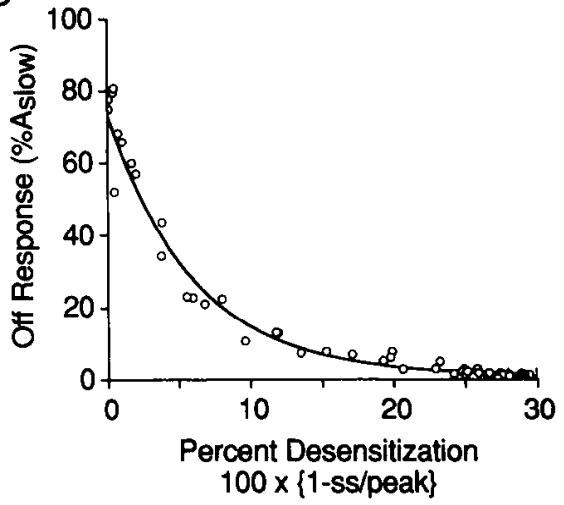

Figure 7. Kinetic analysis of responses to kainate during recovery from the action of cyclothiazide. $A$ shows individual responses from a nucleated patch to rapid application of $3 \mathrm{mM}$ kainatc bcforc (1), during (2), and $44 \mathrm{sec}(3)$ or $72 \mathrm{sec}(4)$ after termination of the application of $100 \mu \mathrm{M}$ cyclothiazide. Traces are from the same experiment illustrated in Figure $6 \mathrm{~A}$, but are plotted on an expanded time range and scaled to have the same peak amplitude; lines drawn through the data points are single-exponential functions fit by least squares. Note that during recovery from the block of desensitization by cyclothiazide, the time constant of onset of desensitization $\left(\tau_{\text {des }}\right)$ does not change. $B$ shows a plot of $\tau_{\text {des }}$ versus percentage desensitization for a series of 42 responses to kainate during recovery from the action of cyclothiazide; the solid circle indicates the mean \pm SD of 30 control responses recorded before and after complete recovery from the action of cyclothiazide. $C$ shows deactivation of responses to kainate following a rapid return to agonist-free solution and recorded before (l), during (2), and $44 \mathrm{sec}$ after (3) termination of the application of cyclothiazide $(1,2$, and 3 indicate the same responses as in $A$ ). Traces are scaled to have the same initial amplitude; lines drawn through the data points are the sum of two exponentials fit by least squares, with time constants $\tau_{\text {fast }}$ and $\tau_{\text {slow }}$ and relative amplitudes $A_{\text {fast }}$ and $A_{\text {slow }}$ as indicated below the traces. $D$ plots the relative amplitude of the slower component of deactivation $\left(A_{\text {slow }}\right)$ versus percentage desensitization for a series of 59 responses to kainate recorded during the application of cyclothiazide and during recovery from its effects; the solid circle shows the mean \pm SD of 30 control responses (as in $B$ above). Recovery from block of desensitization of responses to kainate occurs slower than the decrease in the amplitude of the slow component of deactivation (see also Fig. 6).

and similar to results obtained with whole-cell recording. The peak amplitudes of responses to $3 \mathrm{~mm}$ kainate and $1 \mathrm{~mm}$ glutamate applied to the same patches were $111 \pm 13 \mathrm{pA}$ and 388 $\pm 50 \mathrm{pA}(n=16)$, respectively (Fig. $5 B)$, but their amplitude varied considerably from patch to patch. In individual patches the relative amplitude of responses to kainate and glutamate showed less variability, and the peak amplitude of kainate responses was $30 \pm 1.8 \%$ of the peak glutamate response. However, because kainate produced less desensitization than glutamate, kainate was more efficacious at equilibrium and produced stcady-state responses $10.1 \pm 1.4$ times larger than glutamate.

\section{Kinetic analysis of responses to kainate during modulation by cyclothiazide}

In each of 14 patches studied (11 conventional, 2 nucleated, 1 nystatin vesicle), desensitization evoked by $3 \mathrm{~mm}$ kainate was completely blocked by $100 \mu \mathrm{M}$ cyclothiazide (Fig. 6). In addition, there was marked potentiation of the peak amplitude of responses to kainate (cyclothiazide/control, $2.9 \pm 0.19$ ), and potentiation of the steady-state response (cyclothiazide/control, $4.8 \perp 0.32$ ) was similar to that observed with wholc-ccll rccording. The $10-90 \%$ rise time for responses to $3 \mathrm{~mm}$ kainate was not markedly altered by cyclothiazide (control, $406 \pm 97$ $\mu \mathrm{sec}$; cyclothiazide, $461 \pm 93 \mu \mathrm{sec}$; mean $\pm \mathrm{SD}$, eight patches), but was sufficiently slow that desensitization during the rising phase of the response to agonist would be expected to produce a reduction in peak amplitude (see below). Responses to kainate in outside-out patches decayed rapidly upon return to control solution (Figs. $6 B, 7$ ), and the kinetics of deactivation were well fit by a single exponential function of time constant $825 \pm 178$ $\mu \mathrm{sec}$ (mean $\pm \mathrm{SD}$, eight patches). Responses to kainate recorded from the same patches in the presence of $100 \mu \mathrm{M}$ cyclothiazide showed much slower deactivation (Fig. 6), which in all patches was best fit by the sum of two exponentials with mean time constants $\tau_{\text {fast }}=2.9 \pm 1.6 \mathrm{msec}$ and $\tau_{\text {slow }}=9.5 \pm 3.1 \mathrm{msec}$, with the amplitude of the fast component, $A_{\text {fast }}$, accounting for 62.9 $\pm 18.7 \%$ of deactivation (mean $\pm \mathrm{SD}, n=8$ ). Although the time constants for deactivation in individual patches were sim- 

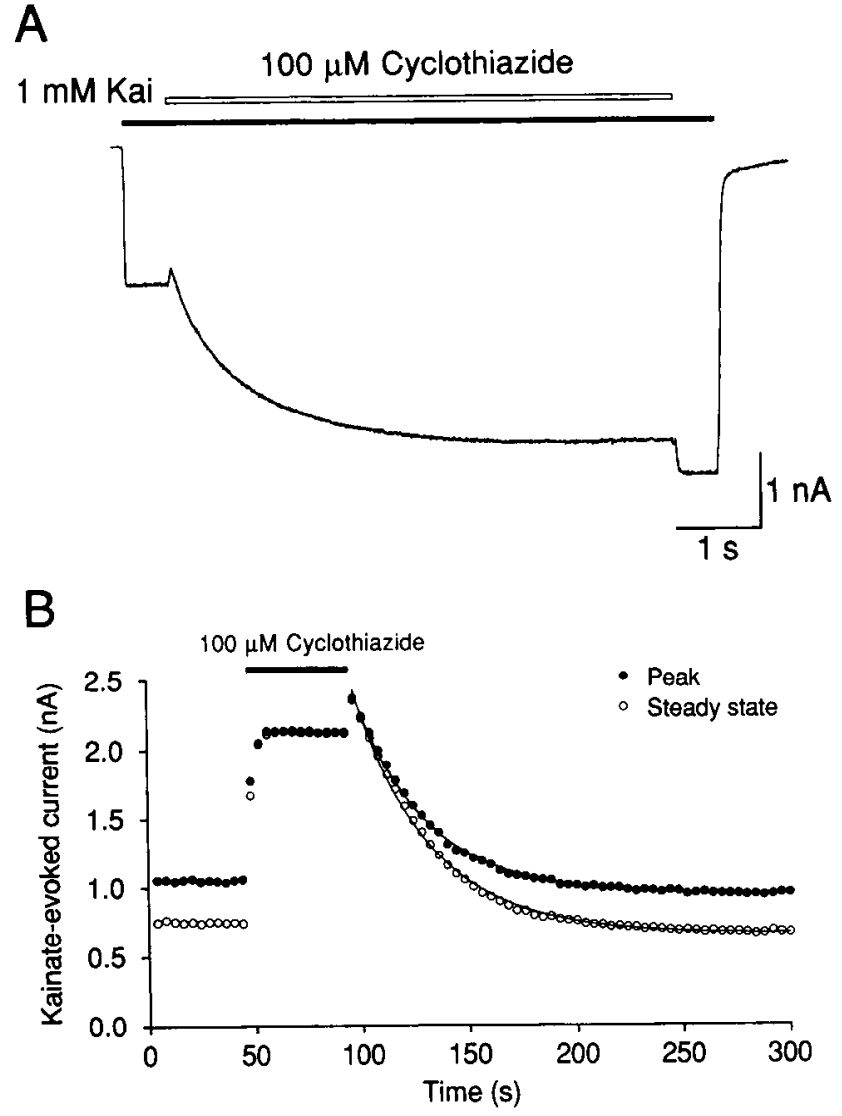

Figure 8. Rapid block and slow potentiation of responses to kainate by cyclothiazide. $A$ shows a whole-cell response during application of $100 \mu \mathrm{M}$ cyclothiazide in the presence of $1 \mathrm{~mm}$ kainate. Immediately following the start of the application of cyclothiazide there was a rapid decrease in current, followed by the slow onset of potentiation, which took approximately $3 \mathrm{sec}$ to reach $90 \%$ of its maximum value. Following termination of the application of cyclothiazide there was a rapid increase in current, which was well described by a single exponential function of time constant $19.1 \mathrm{msec}$. DMSO $(0.5 \%)$ was present in all solutions, and thus did not contribute to the block produced by cyclothiazide. On the time scale shown, recovery from potentiation by cyclothiazide develops too slowly to be visible. $B$ plots the time course of onset of, and recovery from, the action of $100 \mu \mathrm{M}$ cyclothiazide for peak and steadystate responses to $3 \mathrm{~mm}$ kainate in the nucleated patch illustrated in Figure $6 A$; despite solution changes achieved in $\ll 1 \mathrm{msec}$, cyclothiazideevoked potentiation required several seconds to reach a maximum value, and prolonged application of control solution was needed for complete recovery from potentiation. Lines drawn through the data points following the removal of cyclothiazide are least-squares fits of single exponential functions of time constant $35.4 \mathrm{sec}$ (peak) and $34 \mathrm{sec}$ (steady state). The increase in amplitude of responses to kainate recorded immediately following removal of cyclothiazide reflects recovery from block by cyclothiazide prior to the decay of potentiation. Note that for approximately $12 \mathrm{sec}$ after the removal of cyclothiazide responses to kainate continue to show little desensitization, despite a $20 \%$ decrease in amplitude.

ilar, the relative amplitude for $A_{\text {fast }}$ and $A_{\text {slow }}$ varied approximately threefold.

The kinetics of desensitization and deactivation of responses to $3 \mathrm{~mm}$ kainate, recorded before, during, and after the application of $100 \mu \mathrm{M}$ cyclothiazide, wcrc analyzed in greater detail for four patches. In one nucleated patch with an exceptional signal-to-noise ratio, the kinetics of deactivation for control responses to kainate could also be fit by the sum of two exponentials with time constants $\tau_{\text {fast }}=844 \mu \mathrm{sec}$ and $\tau_{\text {slow }}=14.8$ msec, although $A_{\text {slow }}$ accounted for only $0.9 \%$ of the amplitude
(Fig. $7 C$ ); in the other three patches double exponential deactivation kinetics were only observed during the action of cyclothiazide. For the data illustrated in Figure $7 C$ values for $\tau_{\text {fast }}$ and $\tau_{\text {slow }}$ in the presence of cyclothiazide were $2.7 \mathrm{msec}$ and 10.5 msec, respectively, but with $A_{\text {slow }}$ now accounting for $77 \%$ of the amplitude of deactivation. The time constant of onset of desensitization did not change during recovery from the action of cyclothiazide (Fig. $7 A, B$ ) even though the amount of desensitization increased progressively, from a value of zero immediately following termination of the application of cyclothiazide, to $29.8 \%$ after complete recovery from the action of cyclothiazide, comparable to the control value of $28.3 \%$. In contrast to this lack of change in the kinetics of desensitization, the kinetics of deactivation of responses to kainate became progressively faster during recovery from the action of cyclothiazide, and values for both $\tau_{\text {fast }}$ and the relative amplitude of $A_{\text {slow }}$ decreased with time following termination of the application of cyclothiazide, at a faster rate than observed for recovery from block of desensitization (Figs. $7 D, 8 B$ ). Comparable results were obtained in the other three patches analyzed as described above, and in each case the kinetics of desensitization were unaltered during recovery from the action of cyclothiazide, while the kinetics of deactivation of responses to kainate recovered much faster than the block of desensitization.

\section{Slow onset and recovery from potentiation but rapid recovery from block}

Cyclothiazide and related benzothiadazines are lipid-soluble drugs with poor aqueous solubility, and would be expected to partition into the plasma membrane. The onset of potentiation by cyclothiazide in both whole-cell and outside-out patch recordings took several seconds to reach its maximum value (Fig. 8), and following the removal of cyclothiazide potentiation decayed slowly. The onset of potentiation by cyclothiazide applied in the presence of kainate could not be fit by a single exponential function (Fig. $8 \mathrm{~A}$ ) and was not analyzed in detail, but appeared to be complete within $6-8 \mathrm{sec}$ in all cells. The kinetics of recovery from potentiation were most easily studied using brief pulses of agonist (Fig. $8 B$ ), and in outside-out patches the mean time constant for recovery from cyclothiazide-evoked potentiation for stcady-state responses was $37.2 \pm 6.3 \mathrm{sec}$ (six patches); similar results were obtained with whole-cell recording. To test whether the slow kinetics of potentiation by cyclothiazide might be due to diffusion of the drug through the plasma membrane to a cytoplasmic site of action, for five cells we added $100 \mu \mathbf{M}$ cyclothiazide to the intracellular solution used for whole-cell recording. The kinetics and degree of desensitization evoked by $1 \mathrm{~mm}$ L-glutamate were unaffected by intracellular dialysis of cyclothiazide for 6-18 min; however, in the same cells $100 \mu \mathrm{M}$ cyclothiazide abolished desensitization when added to the extracellular solution.

Although cyclothiazide always produced strong potentiation of responses to kainate, we observed additional weak inhibitory effects of cyclothiazide that occurred with distinct kinetics and could not be explained by the presence of DMSO used as a vehicle to make stock solutions of cyclothiazide. The inhibition of responses to kainate by $100 \mu \mathrm{M}$ cyclothiazide was detectable as an initial depression of the response to kainate prior to the onset of potentiation (Fig. $8 \mathrm{~A}$ ), and also as a rapid increase in the response to kainate following a concentration jump to cyclothiazide-free solution (Fig. $8 A, B$ ). This effect of cyclothiazide did not appear to be voltage dependent because in membrane 
patches the increase in amplitude of the response to kainate recorded immediately following termination of the application of cyclothiazide at $-60 \mathrm{mV}$ was similar to that at $+60 \mathrm{mV}$, and comparable to the degree of depression obtained during whole-cell recording at $-60 \mathrm{mV}$. The rate of recovery from inhibition by cyclothiazide was at least 1000 -fold faster than the rate of recovery from cyclothiazide-evoked potentiation: for whole-cell responses in which concentration jumps were made from kainate plus cyclothiazide to kainate alone, the single exponential time constant for recovery from block was $24.1 \pm 2.4$ msec (mean $\pm \mathrm{SD}$, four cells), and possibly limited by the rate of solution exchange, in comparison to the time constant of 37 sec for recovery from potentiation (Fig. $8 B$ ). Once potentiation by $100 \mu \mathrm{M}$ cyclothiazide had reached equilibrium, whole-cell responses to $1 \mathrm{~mm}$ kainate increased in amplitude by $13.4 \pm$ $1.8 \%(n=4)$ on rapidly switching to a solution containing kainate plus $0.5 \%$ DMSO but no cyclothiazide; in the same cells, responses to kainate increased in amplitude by $16.7 \pm 2.6 \%$ upon switching to a solution containing kainate alone. The application of $0.5 \%$ DMSO in the absence of cyclothiazide produced $5.3 \pm 0.5 \%$ inhibition of the control response to kainate. Experiments on outside-out patches gave similar results and the first response to kainate recorded immediately following the removal of cyclothiazide was always larger than the preceding response (Fig. $8 B$ ), reflecting fast recovery from cyclothiazideevoked depression prior to the much slower decay of potentiation. In whole-cell experiments designed to analyze doseresponse curves for the action of cyclothiazide (Figs. 3, 4), potentiation independent of block was studied by measuring responses to kainate in the absence of cyclothiazide. This was achieved by preincubation with cyclothiazide for a sufficiently long period to allow potentiation to reach equilibrium, after which responses to kainate were recorded following a rapid switch to a cyclothiazide-free solution.

\section{Cyclothiazide blocks outward rectification of responses to kainate}

Equilibrium responses to both AMPA and kainate at homomeric and heteromeric glutamate receptors containing GluR2 (GluRB) subunits show weak outward rectification (Boulter et al., 1990; Verdoorn et al., 1991); native AMPA-preferring glutamate receptors in spinal cord and in cortical and hippocampal neurons exhibit similar behavior (Mayer and Westbrook, 1984; Ascher and Nowak, 1988; Jonas and Sakmann, 1992). Experiments on patches from CA1 and CA3 hippocampal neurons suggest that such rectification results from a depolarizationevoked increase in open probability rather than from any voltage dependence of single-channel conductance per se. This is because voltage jumps evoked during responses to AMPA reveal a linear instantaneous $I-V$ relationship followed by time- and voltage-dependent relaxations to levels consistent with the degree of rectification measured at equilibrium (Jonas and Sakmann, 1992). Such rectification could result from voltage dependence of the rate constants for ion channel opening or closing, or from voltage dependence of desensitization. In the present study we used cyclothiazide as a tool to examine this issue.

Consistent with previous studies (e.g., Jonas and Sakmann, 1992), control responses to kainate showed outward rectification during ramp changes in membrane potential (Fig. 9A). However, in contrast to the linear peak $I-V$ relationship for AMPA responses obtained in patches from $\mathrm{CA} 1$ and $\mathrm{CA} 3$ hippocampal

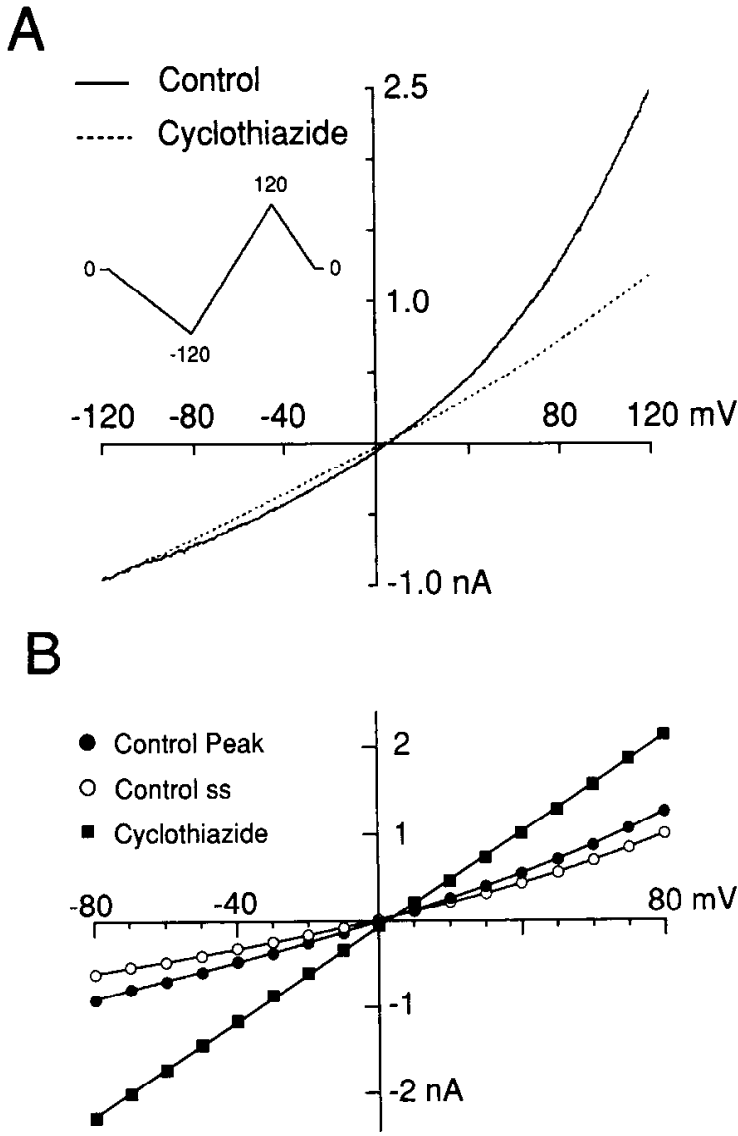

Figure 9. Cyclothiazide blocks outward rectification of responses to kainate. $A$ shows steady-state current-voltage plots for responses to 3 mM kainate obtained from a nucleated patch using a ramp protocol (inset; ramp rates, 0.8 and $1.6 \mathrm{mV} / \mathrm{msec}$ ). Responses are leak subtracted, and show similar rectification during hyperpolarizing and depolarizing ramps; the response to kainate in the presence of cyclothiazide was scaled by 0.23 to have the same amplitude at $-120 \mathrm{mV}$ as the control response. $B$ shows a current-voltage plot of responses to concentration jump application of $3 \mathrm{~mm}$ kainate recorded from another nucleated patch over the membrane potential range of -80 to $+80 \mathrm{mV}$, before and during application of $100 \mu \mathrm{M}$ cyclothiazide. Control responses show outward rectification both at peak and at steady state; in the presence of cyclothiazide the peak and steady-state responses are of equal amplitude, and the current-voltage plot is linear.

neurons (Jonas and Sakmann, 1992), the $I-V$ relationship for control responses to concentration jump application of $3 \mathrm{~mm}$ kainatc showed outward rectification at both peak and steady state (Fig. 9B). In the presence of cyclothiazide, rectification was absent and the $I-V$ relationship for kainate responses was linear in both ramp and concentration jump protocols (Fig. 9A,B). For equilibrium responses to concentration jump application of 3 mM kainate, the ratio of chord conductance at +60 and -60 $\mathrm{mV}\left(G_{+60}: G_{-60}\right)$ was $1.42 \pm 0.02$ for control $(n=4)$, but 0.98 \pm 0.01 in the presence of cyclothiazide $(n=3)$.

Outward rectification was stronger for equilibrium than for peak responses to kainate, with the result that the ratio of steadystate:peak current $\left(I_{s s}: I_{\text {peak }}\right)$ increased with depolarization (Fig. 10). Control responses to kainate desensitized approximately $33 \%$ at $-60 \mathrm{mV}\left(I_{\mathrm{ss}}: I_{\text {peak }}=0.66 \pm 0.02, n=4\right)$, but only $24 \%$ at $+60 \mathrm{mV}\left(I_{\mathrm{ss}}: I_{\text {peak }}=0.76 \pm 0.02, n=3\right)$. In the presence of $100 \mu \mathrm{M}$ cyclothiazide desensitization was abolished and values for $I_{\mathrm{ss}}: I_{\text {peak }}$ at $-60 \mathrm{mV}(0.98 \pm 0.01)$ and $+60 \mathrm{mV}(0.99 \pm 0.01)$ 
A

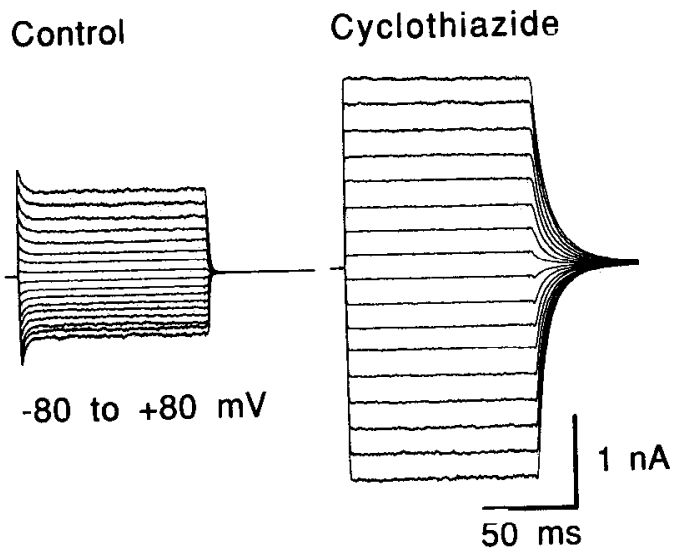

B

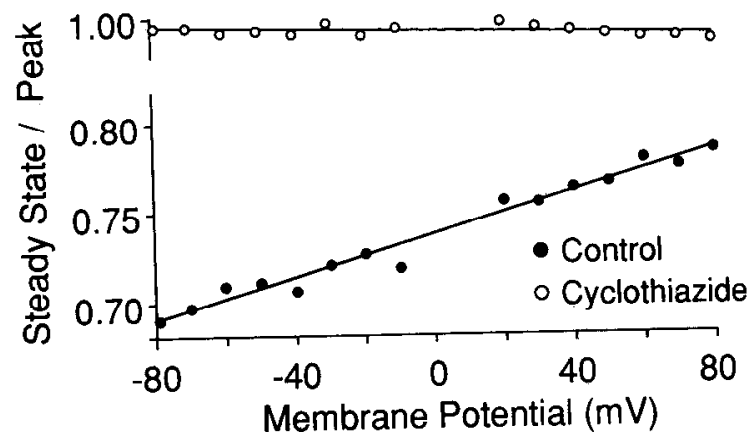

Figure 10. Desensitization evoked by kainate is voltage sensitive. $A$ shows responses to concentration jump application of $3 \mathrm{~mm}$ kainate recorded from a nucleated patch over the membrane potential range -80 to $+80 \mathrm{mV}$, before (left) and during (right) application of $100 \mu \mathrm{M}$ cyclothiazide; note outward rectification for the control responses, and the absence of rectification in the presence of cyclothiazide. $B$ shows the ratio of steady-state:peak current for these responses as a function of membrane potential. The amount of desensitization for control responses to kainate decreases with depolarization, while in the presence of cyclothiazide the ratio of steady-state:peak current is close to unity at all membrane potentials.

were similar and close to unity (Fig. 9). The effects of cyclothiazide strongly suggest that outward rectification of the kainate current-voltage relationship is due to the voltage dependence of desensitization. Consistent with this interpretation, the kinetics of deactivation of responses to kainate did not show any detectable change with membrane potential either in the presence or absence of cyclothiazide.

\section{Kainate acts as a partial agonist following block of desensitization by cyclothiazide}

In control experiments on outside-out patches, $3 \mathrm{~mm}$ kainate evoked peak responses only $30 \%$ of the amplitude of those evoked by $1 \mathrm{~mm}$ glutamate (Fig. 5). Several factors could contribute to this apparent difference in efficacy, including more rapid desensitization to kainate than glutamate during the rising phase of the response to agonists, a partial agonist action of kainate due to differences in open probability, or differences in amplitude of the main conductance state(s) activated by glutamate and kainate. To address the first of these issues we used cyclothiazide as a tool to block desensitization at AMPA-preferring glutamate receptors (Fig. 11). In the presence of $100 \mu \mathrm{M}$ cyclothiazide the
A

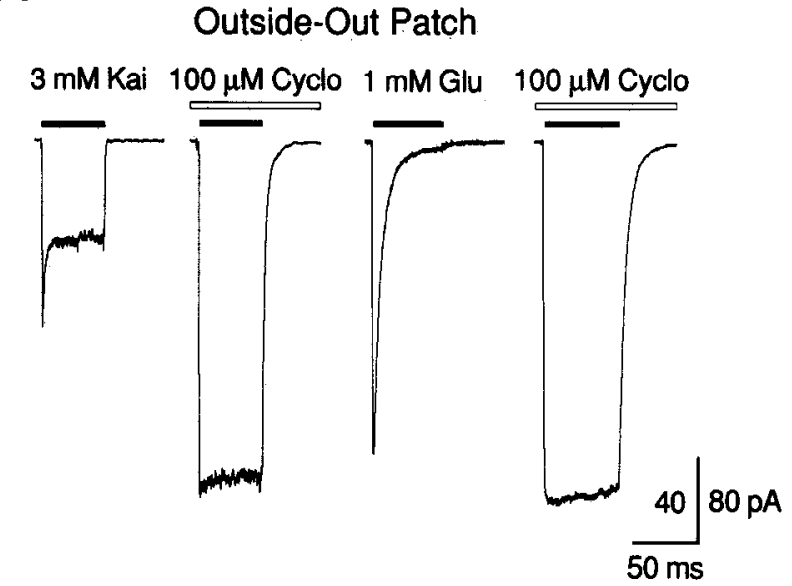

B

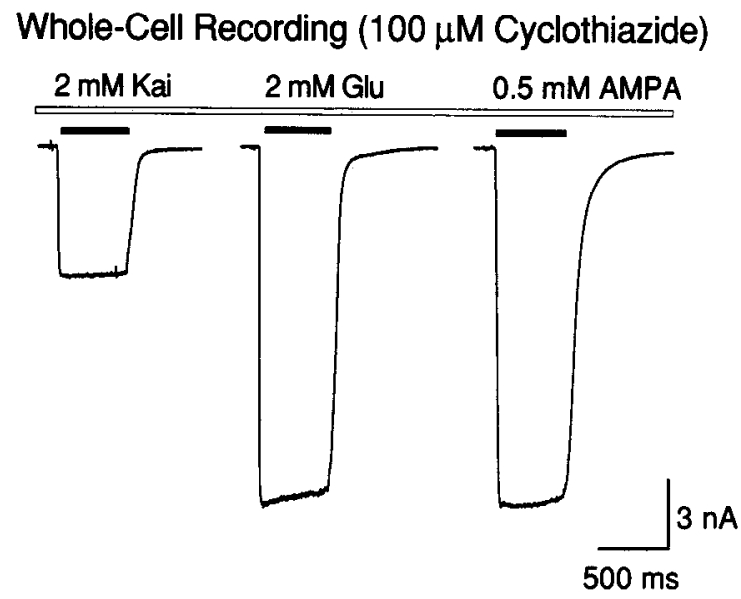

Figure 11. Kainate acts as a partial agonist at AMPA receptors even after complete block of desensitization by cyclothiazide. $A$ shows responses from two outside-out patches to rapid application of $3 \mathrm{~mm}$ kainate (solid bar left) and $1 \mathrm{~mm} S$-glutamate (solid bar right) before and during application of $100 \mu \mathrm{M}$ cyclothiazide (open bars); cyclothiazide eliminates desensitization to both agonists. The 40 and $80 \mathrm{pA}$ calibration bars apply to responses evoked by kainate and glutamate, respectively. Note that cyclothiazide produces a large increase in the peak response to kainate but not glutamate. $B$ shows whole-cell responses to maximally effective doses of kainate, L-glutamate, and $S$-AMPA recorded from the same neuron in the presence of $100 \mu \mathrm{M}$ cyclothiazide; the amplitude of the response to kainate was only 0.36 times that to glutamate and AMPA; similar results were obtained in six neurons. Maximally effective agonist concentrations were determined in separate experiments by dose-response analysis in the presence of cyclothiazide.

peak amplitude of responses to $3 \mathrm{~mm}$ kainate was potentiated $2.9 \pm 0.19$-fold ( 14 patches), while responses to $1 \mathrm{~mm}$ glutamate were potentiated only $1.2 \pm 0.04$-fold ( 9 patches); for both agonists desensitization was completely abolished by cyclothiazide (Fig. 11A). This difference suggests that the larger potentiation by cyclothiazide of the peak response to kainate may in part reflect the faster kinetics of desensitization for kainate relative to glutamate. However, extrapolation of exponential fits of the onset of desensitization to the start of the application of kainate (e.g., Sather et al., 1992) gave estimates for the peak response only $18 \pm 8 \%$ larger than the experimentally determined peak values, suggesting that in addition to block of desensitization by cyclothiazide, additional mechanisms may con- 
tribute to the increase in peak amplitude of responses to kainate. Because desensitization to L-glutamate was greater than that to kainate, potentiation by cyclothiazide for agonist responses measured at equilibrium was much stronger for L-glutamate (74.4 \pm 16 -fold, mean $\pm \mathrm{SEM}, n=8)$ than for kainate $(4.8 \pm$ 0.3 -fold, $n-14$ ). From measurements of the relative amplitude of responses to kainate and glutamate recorded from the same patch, in the absence of cyclothiazide (Fig. 5), and potentiation of responses to these agonists produced by cyclothiazide, when kainate and glutamate were applied to different patches (Fig. $11 \mathrm{~A})$, it is possible to estimate the relative efficacy of these agonists in the absence of desensitization. We calculate that kainate would be expected to produce responses only $70 \%$ of those to glutamate. However, a direct comparison in the same patch between responses to kainate and glutamate, in the presence and absence of cyclothiazide, was not possible with the perfusion system used for outside-out patch recording.

Subsequent experiments to address the issue of whether kainate acts as a partial agonist were performed using whole-cell recording. In experiments on six neurons bathed in $100 \mu \mathrm{M}$ cyclothiazide, we detected no difference in the amplitude of responses to $2 \mathrm{~mm}$ glutamate and $0.5 \mathrm{~mm} S$-AMPA (AMPA: glutamate ratio, $1.00 \pm 0.04$, mean $\pm \mathrm{SD}, 10$ observations), while responses to $2 \mathrm{~mm}$ kainate were considerably smaller than those to AMPA or glutamate (kainate:glutamate ratio, $0.44 \pm$ 0.04 , mean $\pm \mathrm{SD}$ ). The results of such experiments confirm that, even following complete block of desensitization at AMPApreferring glutamate receptors, kainate does appear to act as a partial agonist, but in addition revealed that in the presence of cyclothiazide kainate was even less efficacious than expected from analysis of results from membrane patches.

\section{Discussion}

\section{AMPA-preferring and kainate-preferring glutamate receptors}

Kainate-preferring glutamate receptors expressed in DRG neurons or generated by the expression of GluR5 or GluR6, alone or in combination with $\mathrm{KA} 2$, exhibit desensitization in response to kainate and domoate (IIuettner, 1990; Herb et al., 1992; Sommer and Seeburg, 1992). This raises the possibility that the rapidly desensitizing component of the response to kainate in dissociated cultures of embryonic hippocampal neurons reflects the activation of kainate-preferring rather than AMPA-preferring glutamate receptors. This seems unlikely for the following reasons. First, although responses at kainate-preferring glutamate receptors desensitize in response to kainate, the pharmacology of this response differs substantially from that in hippocampal neurons. For example, lectins eliminate desensitization in response to kainate and domoate at kainate-preferring glutamate receptors (Huettner, 1990; Egebjerg et al., 1991) but do not potentiate responses to kainate or domoate in hippocampal neurons (Mayer and Vyklicky, 1989). Second, in hippocampal neurons the equilibrium dose-response curve for kainate shows no change in Hill coefficient after treatment with cyclothiazide, which is inconsistent with the existence of two distinct populations of receptors, rapidly desensitizing kainate-preferring receptors with high affinity for kainate and nondesensitizing AMPA-preferring receptors with low affinity for kainate. Also, the rapid deactivation kinetics for responses to kainate are inconsistent with activation of a receptor with high affinity for kainate. Third, although the $\mathrm{EC}_{50}$ for kainate responses in hippocampal and DRG neurons differs only 11 -fold, for other agonists such as 5-iodowillardiine the $\mathrm{EC}_{50}$ differs 150 -fold (Patne- au et al., 1992a; Wong et al., 1992). In addition, responses to 5-iodowillardiine are strongly desensitizing in DRG neurons (Wong et al., 1992), but only weakly desensitizing in hippocampal neurons (Patneau et al., 1992a); these results preclude the presence in hippocampal neurons of a sufficient number of kainate-preferring glutamate receptors to give responses detectable by functional analysis when recording from the soma. Finally, preliminary experiments show that cyclothiazide does not reduce desensitization of responses to kainate in DRG neurons (L. Wong and M. L. Mayer, unpublished observations) or in HEK 293 cells transfected with GluR6 and KA2 (D. K. Patneau, M. L. Mayer, and V. Gallo, unpublished observations). It is difficult to explain such agonist- and modulator-specific behavior unless hippocampal and DRG neurons express functionally distinct subtypes of glutamate receptors, which based on current knowledge from analysis of cloned receptors are likely to correspond to AMPA-preferring receptors in hippocampal neurons assembled from GluR 1-GluR4 (GluR-A through GluR-D), and kainate-preferring receptors in DRG neurons assembled from combinations of GluR5-GluR7 together with KAl or KA2.

The results presented here are in accord with our previous work demonstrating that responses to both AMPA and kainate in cultured hippocampal neurons are mediated by the same receptors (Patneau and Mayer, 1991), and therefore lead to the conclusion that kainate does indeed produce substantial, but very rapid, desensitization at AMPA-preferring glutamate receptors. However, our results do not exclude the possibility that kainate-preferring receptors occur in the distal dendrites, axons, or nerve terminals of embryonic hippocampal neurons, sites that would render difficult the detection of functional responses during whole-cell recording from the soma, or from membrane patches removed from the soma. Indeed, in situ hybridization shows the expression in hippocampus of the kainate-preferring subunits GluR5, GluR6, KA1, and KA2 (Bettler et al., 1990; Egebjerg et al., 1991, Herb et al., 1992).

\section{Comparison with previous studies on AMPA-preferring receptors}

Previous studies on native AMPA-preferring glutamate receptors expressed in neurons, as well as in cell lines transfected with subunits from the family GluR1-GluR4 (GluR-A through GluR-D) failed to account for the absence of desensitization in response to kainate and domoate, whereas all other agonists examined produce rapidly and strongly desensitizing responses (Kiskin et al., 1990; Patneau and Mayer, 1990; Sommer et al., 1990). The results presented here show that kainate can produce substantial desensitization at glutamate receptors expressed in patches from cultured hippocampal neurons. The fact that the magnitude and rate of onset of desensitization of responses to kainate were similar in three types of outside-out patch configuration, including nucleated and nystatin-perforated vesicles, indicates that the occurrence of desensitization is unlikely to be an artifact resulting from patch formation. Rather, the very rapid onset of desensitization of kainate responses would preclude its detection in whole-cell recordings even with fast solution exchange. Comparisons in the present study between control responses to glutamate and AMPA obtained with rapid perfusion in whole-cell and outside-out patch recordings indicate that, with the apparatus used for our experiments, the peak amplitude of responses to these agonists (which exhibit fourfold slower desensitization than kainate) is underestimated two- to threefold in whole-cell recordings. 
In two other studies on mammalian neurons, weakly desensitizing responses to kainate were reported (Kiskin et al., 1986, their Fig. 3B; Smith et al., 1991) but such desensitization developed slowly, taking several hundred milliseconds to reach equilibrium, and is unlikely to be related to the rapid responses described here. However, recent experiments on neurons in the chick cochlear nucleus (Raman and Trussell, 1992) described rapidly desensitizing responses to kainate that appear to be similar to those reported here, and were also obtained using a perfusion system capable of submillisecond solution exchange. A recent study of glutamate receptors expressed in Xenopus oocytes following injection of GluR 1 and GluR2 mRNA also supports the conclusion that kainate produces desensitization of AMPA-preferring receptors, with the demonstration that $5 \mathrm{~mm}$ aniracetam potentiated responses to a $100 \mu \mathrm{M}$ (nonsaturating) concentration of kainate by $45 \%$ (Tsuzuki et al., 1992). The lack of effect of either diazoxide or cyclothiazide on kainate responses in other studies (Yamada, 1992; Yamada and Rothman, 1992) remains unexplained.

In the majority of other experiments on mammalian neurons it is not clear that agonists were applied rapidly enough to permit activation of AMPA-preferring glutamate receptors by kainate prior to the onset of desensitization. This is true for analysis of cell lines transfected with the flip and flop forms of subunits for AMPA-preferring glutamate receptors for which solution exchange was estimated to be complete within $20-40 \mathrm{msec}$ (Sommer et al., 1990). A recent study by Jonas and Sakmann (1992) on outside-out patches from CA1 and CA3 hippocampal pyramidal neurons, in which a piezoelectric macroblock element was used to achieve solution exchange within $500 \mu \mathrm{sec}$, would have been expected to show desensitizing kainate responses. However, Jonas and Sakmann rarely applied kainate at concentrations above $300 \mu \mathrm{M}$ and it is unclear whether all of their experiments achieved submillisecond solution exchange because some of the records illustrated show deactivation of responses to kainate with time constants much slower than the $850 \mu \mathrm{sec}$ value reported here. At present it is uncertain whether technical issues account for this difference in response to kainate or if there are functional differences between adult and embryonic neurons. The $\mathrm{EC}_{50}$ values for equilibrium responses to kainate in patches from CA1 $(474 \mu \mathrm{M})$ and CA3 $(344 \mu \mathrm{M})$ neurons are greater than those obtained in whole-cell experiments on embryonic hippocampal neurons $(137 \mu \mathrm{M})$. However, changes in the behavior of AMPApreferring glutamate receptors in intact cells versus isolated membrane patches could contribute to this difference, because we found that the $\mathrm{EC}_{50}$ for kainate applied to patches from embryonic hippocampal neurons $(264 \mu \mathrm{M})$ was larger than obtained with whole-cell recording $(137 \mu \mathrm{M})$. Analysis of the subunit composition of native AMPA-preferring glutamate receptors, and of the kinetics of their response to kainate applied using high-speed perfusion systems, will be required to resolve this discrepancy.

\section{Outward rectification at AMPA-preferring receptors}

Our results suggest that the rectification of responses to kainate, which has been observed in many previous studies (Mayer and Westbrook, 1984; Ascher and Nowak, 1988; Boulter et al., 1990; Verdoorn et al., 1991; Jonas and Sakmann, 1992), results at least in part from a voltage dependence of the rate constants for desensitization, rather than from voltage dependence of the rate constants for ion channel gating, or from voltage-dependent ion channel block by divalent cations (Gu and Huang, 1991). We make this interpretation because over the same membrane potential range that produced a reduction in desensitization with depolarization, we observed no voltage dependence of the kinetics of deactivation following the rapid removal of kainate. Also, in the presence of cyclothiazide the kinetics of deactivation showed no voltage dependence, consistent with the linear current-voltage relationship for responses to kainate and the block of desensitization recorded in the presence of cyclothiazide. For voltage dependence of responses to kainate to arise exclusively from ion channel block by $\mathrm{Ca}$, our results would require that in the presence of cyclothiazide the binding site(s) for Ca within the ion channel must have lower affinity than normal; we have no evidence to exclude this, but note that the effects of cyclothiazide on desensitization and rectification can be more simply explained by voltage dependence of desensitization. However, the birectifying current-voltage relationship of AMPA receptor responses in HEK 293 cells transfected with GluR-A, GluR-C, or GluR-D suggest that other factors can affect rectification in AMPA receptors, especially those that lack GluR-B (Verdoorn et al., 1991). Voltage dependence of desensitization for responses to kainate is consistent with the results of Jonas and Sakmann (1992, their Fig. 14), which showed a reduction with depolarization in the degree of desensitization evoked by AMPA, together with a slowing of the time constant for onset of desensitization; similar results with quisqualate were reported by Thio et al. (1991).

The linear current-voltage relationship for peak responses to AMPA (Jonas and Sakmann, 1992) contrasts with the outward rectification we observed for peak responses to kainate, and probably reflects the slower kinetics of onset of desensitization for AMPA responses compared to those for kainate, such that desensitization interferes with accurate measurement of peak responses to kainate but not AMPA. Recombinant glutamate receptor channels composed of GluR-A and -B also exhibit outward rectification and responses to glutamate show an increase in the steady-state:peak ratio upon depolarization (Verdoorn et al., 1991, their Fig. 1), suggesting that voltage dependence of descnsitization is a common property of AMPA-preferring glutamate receptors containing the GluR-B subunit. Based on differences in the degree of desensitization for flip and flop splice variants (Sommer et al., 1990), rectification might also be expected to vary with subunit composition. The weaker rectification observed in the present study compared to results obtained by Jonas and Sakmann (1992) could arise from differences in receptor subunit composition. However, if rectification does result from a voltage dependence of the rate constants for desensitization, then the degree of rectification should also vary with agonist affinity and concentration. Our results were obtained with a saturating concentration of kainate, while Jonas and Sakmann worked with concentrations below the $\mathrm{EC}_{50}$, at which rectification would be expected to be enhanced; confirming this will require further experimental work.

\section{Desensitization and deactivation kinetics}

Kinetic analysis of concentration jump responses to kainate revealed multiple effects of cyclothiazide: block of desensitization, slowing of deactivation, an increase in maximal response, and a shift to the left of the kainate dose-response curve. These effects are all consistent with an increase in open probability, but whether cyclothiazide produces its effects via a single or multiple mechanism(s) is unclear. The results of our experiments provide much new information concerning the gating of 
AMPA-preferring glutamate receptors by kainate, but additional data are required to distinguish clearly between several alternative schemes that could underlic the effects of cyclothiazide. Possible mechanisms include (1) block of desensitization (due to either a slowing of the rate of entry into the desensitized state, a speeding up of the rate of recovery from desensitization, or a steric effect preventing the conformational change that underlies desensitization), (2) an increase in affinity for kainate, and (3) a slowing of the closing rate constant for ion channel gating.

Although the deactivation of control responses to kainate was well fit by a single exponential function of time constant 825 $\mu \mathrm{sec}$, suggesting that only a single open state is populated at a detectable frequency (but see Fig. 7), the double exponential time course of deactivation in the presence of cyclothiazide is consistent with the occurrence of two or more open states (as shown below):

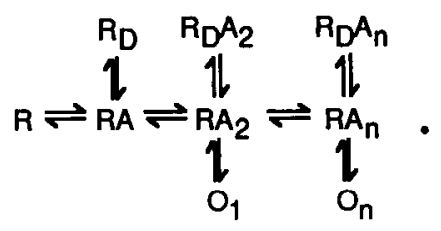

One mechanism of action of cyclothiazide could be to change the relative occupancy of the open states, such that channels spend more time in the state(s) associated with prolonged bursts of openings (deactivation time constants in the presence of cyclothiazide were 2.9 and $9.5 \mathrm{msec}$ ). Because the amplitude of the maximum response to kainate increases over threefold in the presence of cyclothiazide, either the conductance of the open states must be different, or the ratio of the closing rate constants to the opening and agonist dissociation rate constants must be such that in the absence of cyclothiazide the average open probability for kainate-activated receptors is considerably less than one.

An alternative mechanism of action of cyclothiazide would be to slow the closing rate constants for ion channel gating, if as shown above, entry into desensitized states $\left(R_{D}\right)$ proceeded from agonist bound closed (RA) but not open states $(O)$. This raises the possibility that, during activation of AMPA-preferring glutamate receptors by kainate, entry into desensitized states normally limits the number of openings per burst, and that the slowing of deactivation produced by cyclothiazide occurs secondarily to block of desensitization. This would increase the number of openings per burst, and hence the amplitude of the equilibrium response to a saturating concentration of kainate. However, even a 10 -fold slowing by cyclothiazide of the closing rate constants for ion channel closing would probably not be sufficient to abolish desensitization, suggesting that cyclothiazide must additionally affect entry into desensitized states per se.

Another potential mechanism of action of cyclothiazide has precedent from work on mutant $\alpha 7$ nicotinic receptors (Revah et al., 1991) in which a leucine to threonine substitution in the second transmembrane region was proposed to alter the conductance of the desensitized state. Because so little is known concerning the molecular events during desensitization in ligand-gated ion channels, it is unclear whether a drug could prevent the conformational change to a nonconducting (or blocked) state during desensitization. For all ligand-gated re- ceptors studied to date, agonists bind to desensitized states with higher affinity than to resting or active states. Although the leftward shift of the dose-response curve for kainate produced by cyclothiazide would be consistent with channel opening during desensitization, changes in the rate constants for ion channel gating, or for binding of kainate, would produce a similar effect (Ogden et al., 1987).

\section{The slow onset of and recovery from potentiation by cyclothiazide}

The slow kinetics of action of cyclothiazide could arise from a variety of mechanisms. Of note, the low potency of cyclothiazide $\left(\mathrm{EC}_{50}, 9 \mu \mathrm{M}\right)$ combined with the unusually slow rate of recovery from potentiation (time constant, $37 \mathrm{sec}$ ) is inconsistent with diffusion limited binding to a site freely accessible from the aqueous phase. The possibility that cyclothiazide partitions into the plasma membrane lipid bilayer has precedent from work on ATP-sensitive potassium channels, one target of action of the structurally related drug diazoxide (Quast and Cook, 1989). Although it is unlikely that the mechanism of action of diazoxide on ATP-sensitive potassium channels is similar to that for the action of cyclothiazide on AMPA receptors, work on ATP-sensitive potassium channels in pancreatic $\beta$-cells and in cardiac myocytes reveals unusually slow kinetics of recovery from inhibition by sulfonylureas, the kinetics of which vary with the concentration and length of application of drug and with the extracellular $\mathrm{pH}$, suggesting partitioning of sulfonylureas into the plasma membrane (Zünkler et al., 1989; Findlay, 1992a,b). Further experiments are required to determine if cyclothiazide must enter the lipid bilayer to reach its site of action on AMPA receptors, but the observation that cyclothiazide is inactive when added to the intracellular solution implies that, unlike sulfonylureas, cyclothiazide cannot cross lipid bilayers and must act at an extracellular site.

During slow recovery from potentiation by cyclothiazide the kinetics of desensitization do not vary as the block of desensitization by cyclothiazide decreases, as though one population of receptors is desensitizing rapidly, with normal kinetics, while the other does not desensitize at all. Such behavior could occur if there were two populations of AMPA-preferring glutamate receptors, those with cyclothiazide bound and those from which cyclothiazide has already dissociated. Our observation that the time constant of the rapid component of deactivation of responses to kainate becomes progressively faster during recovery from the action of cyclothiazide, appears to contradict this hypothesis, but can be explained by our inability to distinguish between a single exponential of intermediate time constant, and deactivation due to the sum of exponentials of similar time constants (control, $0.8 \mathrm{msec}$; cyclothiazide, $2.9 \mathrm{msec}$ ), the relative weights of which vary with time during recovery from the action of cyclothiazide.

An alternative mechanism consistent with the above observations would be regulation of AMPA receptor gating via an allosteric mechanism, with the kinetics of onset of and recovery from the action of cyclothiazide determined by the rate constants for transitions between AMPA receptor conformations that gate ion channel activity with low and high probability. Measurement of the temperature dependence of the action of cyclothiazide, or of the kinetics of action of structurally related benzothiadiazines could potentially help to distinguish between alternative mechanisms. 
Kainate acts as a partial agonist at AMPA-preferring glutamate receptors

The results of our study show that a saturating concentration of kainate produces responses less than $50 \%$ of the amplitude of those evoked by AMPA and glutamate. The origin of this difference in efficacy was not further addressed in the present experiments, but may represent agonist-dependent differences in both single-channel conductance and open probability. Many studies have shown that, on average, the conductance of channels activated by kainate is less than that for other agonists while spectral analysis indicates longer open times or burst lengths for AMPA and glutamate than for kainate, suggesting agonistdependent differences in open probability (e.g., Ascher and Nowak, 1988; Cull-Candy and Usowicz, 1989; Jonas and Sakmann, 1992). The substantial desensitization of AMPA-preferring glutamate receptors that occurs during equilibrium responses would have affected the measurement of single-channel kinetics in previous work with these agonists. The complete block of desensitization by cyclothiazide provides a powerful new tool for the analysis of AMPA-preferring glutamate receptors independent of desensitization, and could permit resolution of the single-channel mechanisms underlying differences in the efficacy of AMPA and kainate.

\section{References}

Ascher P, Nowak, L (1988) Quisqualate- and kainate-activated channels in mouse central neurones in culture. J Physiol (Lond) 399:227245.

Bettler B, Boulter J, Hermans-Borgmeyer I, O'Shea-Greenfield A, Deneris ES, Moll C, Borgmeyer U, Hollmann M, Heinemann S (1990) Cloning of a novel glutamate receptor subunit, GluR5: expression in the nervous system during development. Neuron 5:583-595.

Bettler B, Egebjerg J, Sharma G, Pecht G, Hermans-Borgmeyer I, Moll C, Stevens CF, Heinemann S (1992) Cloning of a putative glutamate receptor: a low affinity kainate-binding subunit. Neuron 8:257-265.

Boulter J, Hollmann M, O'Shea-Greenfield A, Hartley M, Deneris E, Maron C, Heinemann S (1990) Molecular cloning and functional expression of glutamate receptor genes. Science 249:1033-1037.

Colquhoun D, Ogden DC (1988) Activation of ion channels in the frog end-plate by high concentrations of acetylcholine. I Physiol (Lond) 395:131-159.

Cull-Candy SG, Usowicz MM (1989) On the multiple-conductance single channels activated by excitatory amino acids in large cerebellar neurones of the rat. J Physiol (Lond) 415:555-582.

Egebjerg J, Bettler B, Hermans-Borgmeyer I, Heinemann S (1991) Cloning of a cDNA for a glutamate receptor subunit activated by kainate but not AMPA. Nature 351:745-748.

Findlay I (1992a) Inhibition of ATP-sensitive $\mathrm{K}^{+}$channels in cardiac muscle by the sulphonylurea drug glibenclamide. J Pharmacol Exp Ther 261:540-545.

Findlay I (1992b) Effects of $\mathrm{pH}$ upon the inhibition by sulphonylurea drugs of ATP-sensitive $\mathrm{K}^{+}$channels in cardiac muscle. J Pharmacol Exp Ther 262:71-79.

Gu Y, Huang LYM (1991) Block of kainate receptor channels by $\mathrm{Ca}^{2+}$ in isolated spinal trigeminal neurons of rat. Neuron 6:777-784.

Hamill OP, Marty A, Neher E, Sakmann B, Sigworth FJ (1991) Improved patch-clamp techniques for high-resolution current recording from cells and cell-free membrane patches. Pfluegers Arch 391:85100.

Herb A, Burnashev N, Werner P, Sakmann B, Wisden W, Seeburg PH (1992) The KA-2 subunit of excitatory amino acid receptors shows widespread expression in brain and forms ion channels with distantly related subunits. Neuron 8:775-785.

Horn R, Marty A (1988) Muscarinic activation of ionic currents measured by a new whole-cell recording method. J Gen Physiol 92:145159.

Huettner JE (1990) Glutamate receptor channels in rat dorsal root ganglion neurons: activation by kainate and quisqualate, and blockade of desensitization by concanavalin A. Neuron 5:255-266.
Isaacson JS, Nicoll RA (1991) Aniracetam reduces glutamate receptor desensitization and slows the decay of fast excitatory synaptic currents in the hippocampus. Proc Natl Acad Sci USA 88:10936-10940.

Ito I, Tanabe S, Kohda A, Sugiyama H (1990) Allosteric potentiation of quisqualate receptors by a nootropic drug aniracetam. J Physiol (Lond) 424:533-543.

Jonas P, Sakmann B (1992) Properties of AMPA subtype glutamate receptors in pyramidal cells of rat hippocampus. J Physiol (Lond) 455:143-171.

Keinänen K, Wisden W, Sommer B, Werner P, Herb A, Verdoorn TA, Sakmann B, Seeburg PH (1990) A family of AMPA-selective glutamate receptors. Science 249:556-560.

Kiskin NI, Krishtal OA, Tsyndrenko AY (1986) Excitatory amino acid receptors in hippocampal neurons: kainate fails to desensitize them. Neurosci Lett 63:225-230.

Kiskin NI, Krishtal OA, Tsyndrenko AY (1990) Cross-desensitization reveals pharmacological specificity of excitatory amino acid receptors in isolated neurons. Eur J Neurosci 2:461-470.

Levitan ES, Kramer RH (1990) Neuropeptide modulation of single calcium and potassium channels detected with a new patch clamp configuration. Nature 348:545-547.

Mayer ML, Vyklicky L Jr (1989) Concanavalin A selectively reduces desensitization of mammalian neuronal quisqualate receptors. Proc Natl Acad Sci USA 86:1411-1415.

Mayer ML, Westbrook GL (1984) Mixed-agonist action of excitatory amino acids on mouse spinal cord neurones under voltage clamp. J Physiol (Lond) 354:29-53.

Mayer ML, Vyklicky L, Westbrook GL (1989) Modulation of excitatory amino acid receptors by group IIB metal cations in cultured mouse hippocampal neurones. J Physiol (Lond) 415:329-350.

Mayer ML, Patneau DK, Vyklicky L (1992) Desensitization, drugs, and synaptic transmission at AMPA/kainate receptors. In: Excitatory amino acids (Simon RP, ed), pp 125-131. New York: Thieme.

Ogden DC, Colquhoun D, Marshall CG (1987) Activation of nicotinic ion channels by acetylcholine analogues. In: Cellular and molecular basis of cholinergic function (Dowdall MJ, Hawthorne JN, eds), pp 133-151. Chichester: Ellis Horwood.

Patneau DK, Mayer ML (1990) Structure-activity relationships for amino acid transmitter candidates acting at $N$-methyl-D-aspartate and quisqualate receptors. J Neurosci 10:2385-2399.

Patneau DK, Mayer ML (1991) Kinetic analysis of interactions between kainate and AMPA: evidence for activation of a single receptor in mouse hippocampal neurons. Neuron 6:785-798.

Patneau DK, Mayer ML, Jane DE, Watkins JC (1992a) Activation and desensitization of AMPA/kainate receptors by novel derivatives of willardiine. J Neurosci 12:595-606.

Patneau DK, Vyklicky L, Mayer M (1992b) Cyclothiazide modulates excitatory synaptic transmission and AMPA/kainate receptor desensitization. Soc Neurosci Abstr 18:248.

Quast U, Cook NS (1989) Moving together: $\mathrm{K}^{+}$channel openers and ATP-sensitive $\mathrm{K}^{+}$channels. Trends Pharmacol Sci 10:431-435.

Raman IM, Trussell LO (1992) The kinetics of the response to glutamate and kainate in neurons of the avian cochlear nucleus. Neuron 9:173-186.

Revah F, Bertrand D, Galzi JL, Devillers-Thièry A, Mulle C, Hussy N, Bertrand S, Ballivet M, Changeux JP (1991) Mutations in the channel domain alter desensitization of a neuronal nicotinic receptor. Nature 353:846-849.

Sather W, Dieudonné S, MacDonald J, Ascher P (1992) Activation and desensitization of $N$-methyl-D-aspartate receptors in nucleated outside out-patches from mouse neurones. J Physiol (Lond) 450:643672.

Sommer B, Seeburg PH (1992) Glutamate receptor channels: novel properties and new clones. Trends Pharmacol Sci 13:291-296.

Sommer B, Keinänen K, Verdoorn TA, Wisden W, Burnashev N, Herb A, Kohler M, Takagi T, Sakmann B, Seeburg PH (1990) Flip and flop: a cell-specific functional switch in glutamate-operated channels of the CNS. Science 249:1580-1585.

Smith DO, Franke C, Kosenheimer JL, Zufall F, Hatt H (1991) Desensitization and resensitization rates of glutamate activated channels may regulate motoneuron excitability. J Neurophysiol 66:1166-1175.

Tang CM, Shi QY, Katchman A, Lynch G (1991) Modulation of the time course of fast EPSCs and glutamate channel kinetics by aniracetam. Science 254:288-290.

Thio LL, Clifford DB, Zorumski CF (1991) Characterization of quis- 
qualate receptor desensitization in cultured postnatal rat hippocampal neurons. J Neurosci 11:3430-3441.

Trussell LO, Thio LL, Zorumski CF, Fischbach GD (1988) Rapid desensitization of glutamate receptors in vertebrate central neurons. Proc Natl Acad Sci USA 85:2834-2838.

Tsuzuki K, Takeuchi T, Ozawa S (1992) Agonist- and subunit-dependent potentiation of glutamate receptors by a nootropic drug aniracetam. Mol Brain Res 16:105-110.

Verdoorn TA, Burnashev N, Monyer H, Seeburg PH, Sakmann B (1991) Structural determinants of ion flow through recombinant glutamate receptor channels. Science 252:1715-1718

Vyklicky L, Benveniste M, Mayer ML (1990) Modulation of $N$-methyl-D-aspartic acid receptor desensitization by glycine in cultured mouse hippocampal ncurones. J Physiol (Lond) 428:313-331.

Vyklicky L Jr, Patneau DK, Mayer ML (1991) Modulation of excitatory synaptic transmission by drugs that reduce desensitization at AMPA/kainate receptors. Neuron 7:971-984.

Werner P, Voigt M, Keinänen K, Wisden W, Seeburg PH (1991) Clon- ing of a putative high-affinity kainate receptor expressed predominantly in hippocampal CA3 cells. Nature 351:742-744.

Wong LA, Mayer ML, Jane DE, Watkins JC (1992) Characterization of kainate receptors in rat dorsal root ganglion (DRG) neurons using novel $S$-willardiine analogs. Soc Neurosci Abstr 18:86.

Yamada KA (1992) Thiazide diuretics reversibly block postsynaptic glutamate receptor desensitization in rat hippocampal neurons. Soc Neurosci Abstr 18:757.

Yamada KA, Rothman SM (1991) Diazoxide reversibly blocks glutamate desensitization and prolongs excitatory postsynaptic currents. Soc Neurosci Abstr 17:896.

Yamada KA, Rothman SM (1992) Diazoxide reversibly blocks glutamate desensitization and prolongs excitatory postsynaptic currents in rat hippocampal neurons. J Physiol (Lond) 458:385-407.

Zünkler BJ, Trube G, Panten U (1989) How do sulfonylureas approach their receptor in the $\beta$-cell membrane? Naunyn Schmiedebergs Arch Pharmacol 340:328-332. 